\title{
Effector Specificity in Macaque Frontal and Parietal Cortex
}

\author{
Elsie Premereur, ${ }^{1}$ @Peter Janssen, ${ }^{1}$ and $\odot W i m$ Vanduffel ${ }^{1,2,3}$ \\ ${ }^{1}$ Laboratory for Neurophysiology and Psychophysiology, KU Leuven, 3000 Leuven, Belgium, ${ }^{2}$ Athinoula A. Martinos Center for Biomedical Imaging, \\ Massachusetts General Hospital, Charlestown, Massachusetts 02129, and ${ }^{3}$ Department of Radiology, Harvard Medical School, Boston, Massachusetts 02114
}

\begin{abstract}
Single neurons in the frontal eye fields (FEFs) and lateral intraparietal area (LIP) of macaques are preferentially activated by saccadeversus reach-related processes. fMRI studies focusing on saccade- and reach-specific activity in human cortex, however, provided conflicting evidence for effector specificity. To gain further insights into effector preferences throughout monkey cortex using the same technique as in humans, we performed a mixed block/event-related fMRI experiment in macaques. Within single fMRI runs, monkeys alternated between a visually guided saccade task, a visually guided arm movement task, and a fixation-only task requiring no saccades or arm movements. The detection of a peripheral pop-out go cue initiating the required operant behavior and the identification of a target among distractors was identical in the arm and saccade tasks. We found saccade-related activity in parietal areas V6, V6A, LIP, and caudal intraparietal area and frontal areas FEF, 45a, 45b, and 46. Areas 45 and FEF even showed markedly decreased fMRI activity during arm movements relative to fixation only. Conversely, medial and anterior intraparietal areas (MIP and AIP), and parietal area PEip; somatosensory areas S1 and S2; and (pre)motor areas F1, F3, F5, and F6 showed increased arm movement-related activity. F1, F5, PEip, and somatosensory cortex also showed deactivations during saccades relative to fixation only. Control experiments showed that such deactivations in both operant-specific functional networks did not depend on training history or rapid task switching requiring active suppression of the unpreferred operant behavior. Therefore, although both tasks required divided attention to detect a pop-out go cue and target, two largely segregated and mainly effector-driven cortical networks were activated.
\end{abstract}

Key words: fMRI; saccades

\section{Introduction}

Macaque electrophysiology has identified several effector-specific subdivisions in posterior parietal cortex (PPC). Lateral intraparietal area (LIP) neurons fire during planning and execution of saccades, whereas cells in the medial bank of the intraparietal sulcus (IPS), including medial intraparietal area (MIP) and V6A, are activated during planning and execution of arm movements (Duhamel et al., 1992; Colby et al., 1996; Platt and Glimcher, 1997; Snyder et al., 1997; Fattori et al., 2001; Pesaran et al., 2002; Wardak et al., 2002; Scherberger et al., 2005; Thomas and Paré, 2007; Kagan et al., 2010). Downstream areas from LIP, including the frontal eye fields (FEFs) and superior colliculus, are also implicated in saccades (Schiller et al., 1987; Munoz and Wurtz, 1995; Schall et al., 1995; Stanton et al., 1995; Everling et al., 1999; Ferraina et al., 2002; Peel et al., 2014). Neurons in MIP and V6A, conversely, project to dorsal premotor cortex (Johnson et al.,

Received Sept. 5, 2014; revised Jan. 15, 2015; accepted Jan. 16, 2015.

Author contributions: E.P., P.J., and W.V. designed research; E.P. performed research; E.P. analyzed data; E.P., P.J., and W.V. wrote the paper.

This work was supported by the Research Foundation Flanders (FW0 grants G0A5613N, G062208.10, G083111.10, G059309); Geconcerteerde onderzoeksacties GOA/10/19; Inter university attraction poles IUAP VII/11; Program Financing PFV/10/008; Odysseus G0007.12, and the Hercules foundation. We thank Anne Coeman, Stijn Verstraeten, Piet Kayenbergh, Gerrit Meulemans, Marc De Paep, and Inez Puttemans for assistance and Steve Raiguel for comments on a previous version of this manuscript.

The authors declare no competing financial interests.

Correspondence should be addressed to Wim Vanduffel, KU Leuven, Laboratorium voor Neuro-en Psychofysiologie, 0\&N II Herestraat 49-bus 1021, 3000 Leuven, Belgium. E-mail: Wim.Vanduffe@@med.kuleuven.be.

DOI:10.1523/JNEUROSCI.3710-14.2015

Copyright $\odot 2015$ the authors $\quad 0270-6474 / 15 / 353446-14 \$ 15.00 / 0$
1996; Marconi et al., 2001). These anatomical connections and functional properties indicate that areas LIP and MIP/V6A are important nodes of a saccade and reach network, respectively (Snyder et al., 2000; Lawrence and Snyder, 2006).

This functional distinction, however, is not strict because both LIP and MIP/V6A contain neurons responsive to the "nonpreferred” effector (Snyder et al., 1997; Lawrence and Snyder, 2006). Furthermore, the degree of functional specialization within human PPC is less clear than in monkeys. Studies showing limited effector specificity (Levy et al., 2007; Beurze et al., 2009; Heed et al., 2011) conflicted with those showing effector-specific signals for hand or eye movements (see Vesia and Crawford, 2012). Indeed, human magnetoencephalography showed distinct PPC modules encoding the movement goals of saccades versus reaching (Van Der Werf et al., 2008; Van Der Werf et al., 2010) and human fMRI studies indicated clear effector-specific signals (Connolly et al., 2003; Medendorp et al., 2005; Hinkley et al., 2009; Gallivan et al., 2011).

In addition, Levy et al. (2007) described a lack of effector selectivity in human FEF. This finding contrasts with previous monkey electrophysiology showing that FEF neurons are more involved in saccades than reaches (Goldberg and Bushnell, 1981; Lawrence and Snyder, 2006). Similarly, Connolly et al. (2007) described a lack of effector specificity in human FEF, except for its ventral part.

To gain insight into effector preferences and specificities in monkeys and to enable a direct comparison of monkey and human data, we trained macaques to alternate between saccades and arm movements in a mixed block/event-related fMRI experi- 
A

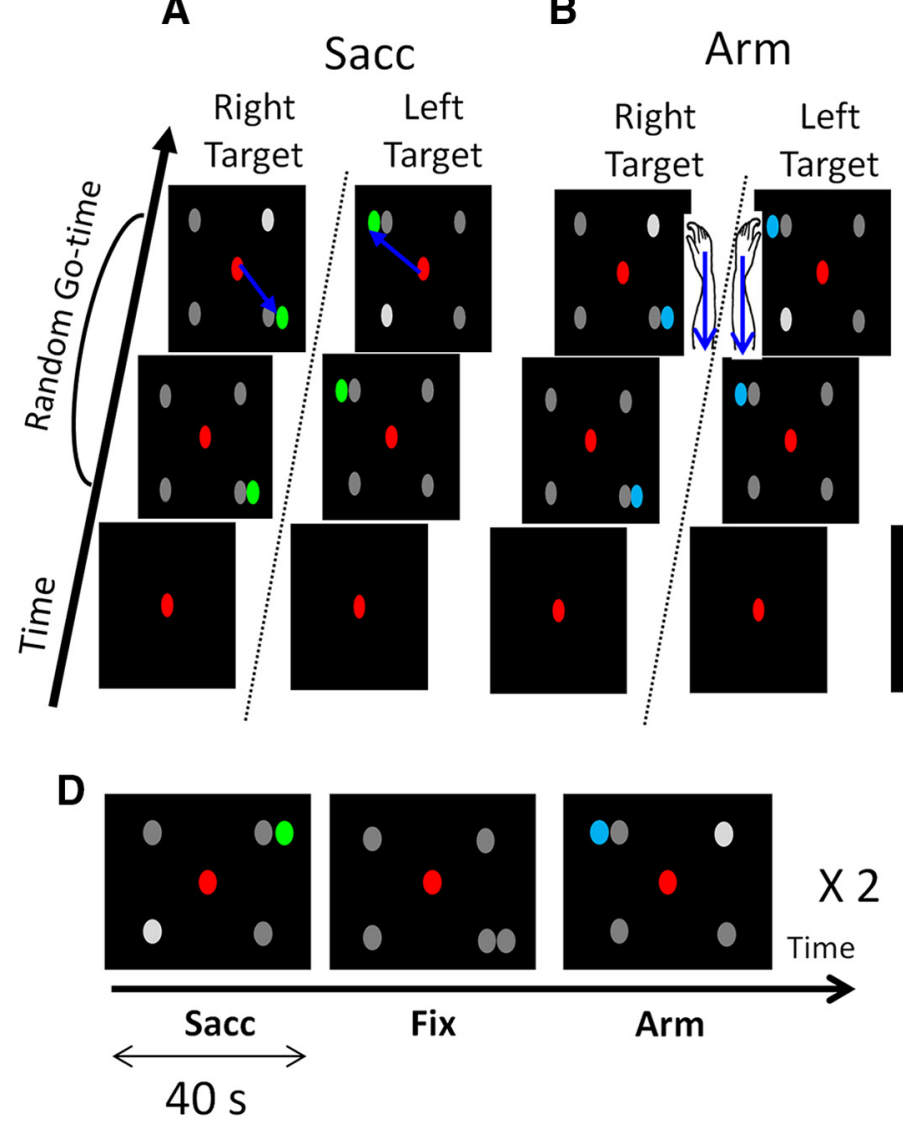

c

Fix

Right Left

Distractor Distractor

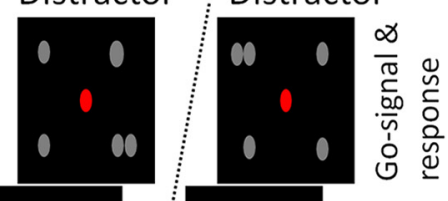
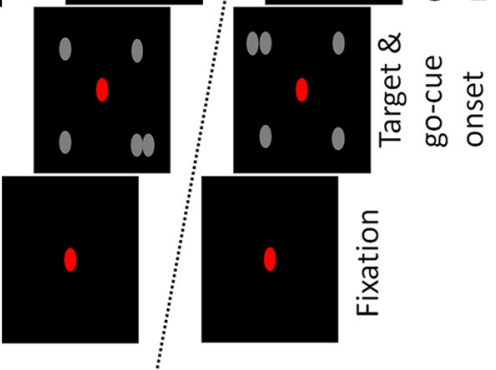

E

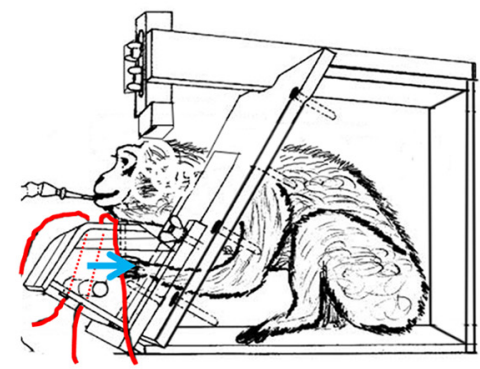

Figure 1. Methods. A, Sacc with multiple possible go cues. After a brief period of fixation, four gray possible go cues and one green saccade target appeared. One of the gray possible go cues increased in luminance after a random go time, indicating to the monkey to saccade toward the green target (indicated by the blue arrow). $\boldsymbol{B}$, Arm with multiple possible go cues. The blue target indicated to the monkey to retract the arm (indicated with the blue arrow) ipsilateral to the target after the go signal. $\boldsymbol{C}$, Fixation task with multiple distractors. The gray color of the fifth distractor, together with the lack of a go signal, indicated to the subject to maintain central fixation. D, Block design fMRI experiment showing, respectively, a Sacc task, a Fix task with five distractors, and an Arm task. Every task is presented for $40 \mathrm{~s}$. During the actual experiment, the conditions were presented in random order in one cycle and a cycle was presented twice in each run. $\boldsymbol{E}$, Monkey in sphinx position (adapted from Vanduffel et al., 2001). Red lines indicate the optic fibers for the infrared laser beams (a pair for the left and for the right hand). Fibers are positioned below and above the bar serving as rest position for the hand. Red dotted lines indicate the uninterrupted laser beam. The monkey had to retract the left hand when the target appeared in the left hemifield and the right arm when it appeared on the right. Blue arrow indicates the direction of the response movement.

ment. During both tasks, the monkeys had to indicate the position of a target immediately after a go signal that could appear randomly in any of the four quadrants. Consistent with monkey electrophysiology, our results revealed strong effector-specific activations. Furthermore, several key areas of the saccade and arm movement networks were actually deactivated by the nonpreferred effector. Therefore, in the macaque, distinct effectorspecific networks can be observed using fMRI. The current results confirm previous monkey electrophysiology and several, but not all, human imaging studies.

\section{Materials and Methods}

Surgery

All experiments were performed using four male rhesus monkeys (Macaca mulatta): juvenile Monkeys R (4 kg) and $\mathrm{S}(5 \mathrm{~kg})$ and adult Monkeys U (5.8 kg) and K (6 kg). Two monkeys (Monkey U and Monkey $\mathrm{R}$ ) were used in the main experiment and two (Monkey K and Monkey S) in a control experiment. After training to sit in a primate chair, a custommade head post was implanted on the skull using ceramic screws and dental acrylic. At least 6 weeks after surgery, the monkeys began training in passive fixation and eye and arm movement tasks. All procedures were performed in accordance with the National Institutes of Health's Guide for the Care and Use of Laboratory Animal and the European legislation (Directive 2010/63/EU) and were approved by the Ethical Committee at the KU Leuven.

\section{Training}

Monkeys were trained in a mock fMRI setup. They were seated in a sphinx position (Vanduffel et al., 2001) in a plastic monkey chair directly facing an LCD screen (viewing distance: $57 \mathrm{~cm}$ ). Eye position was monitored at $120 \mathrm{~Hz}$ through the pupil position (Iscan).

\section{Tasks}

In the main experiment, three types of tasks were presented to the animals in blocks: a passive fixation task (Fix), a visually guided saccade task (Sacc), and a visually guided arm movement task (Arm) (Fig. 1A-D). Monkey $\mathrm{R}$ was first trained in the Sacc task, followed by training in the arm-movement task; the reverse was true for Monkey $\mathrm{U}$.

Sacc. The animal had to maintain fixation within a $2 \times 2$ degree window around a small red spot in the center of a black display for a fixed period of $200 \mathrm{~ms}$, after which a single green saccade target and four possible gray go cues appeared (Fig. 1A; Premereur et al., 2011). Target and go cues were equal in size $\left(0.27^{\circ}\right)$ and luminance $\left(6 \mathrm{~cd} / \mathrm{m}^{2}\right)$. The saccade target appeared randomly in either the left or right visual field. Three different stimulus configurations were used in different runs: the target was shown in the upper left or lower right corner (135 and -45 degree angle from horizontal; 17 degrees eccentricity), in the lower left or upper right corner ( -135 and 45 degree angle, 17 degree eccentricity), or to the left or right of the center of the screen along the horizontal axis (12 degrees eccentricity). The four possible go cues appeared simultaneously in the four quadrants, with one of them always next to the saccade target (Fig. 1A). Different stimulus configurations were used in alternating runs 
within a daily session and results were averaged over runs and thus over stimulus configurations. After a variable delay (between 500 and 2000 $\mathrm{ms}$ ), the luminance of one of the four gray go cues (randomly selected) increased by $300 \%$ (a pop-out go signal), indicating to the animal to make a saccade toward the green target. The animal was rewarded for a saccade toward the target within $700 \mathrm{~ms}$ after the go signal, followed by a period of $250 \mathrm{~ms}$ during which its gaze had to remain within a 3-4 degree window surrounding the target.

Four peripherally presented go cues were used to ensure that the animals were maximally attending all four quadrants simultaneously to detect the go signal. To encourage rapid responses, reward size was governed by an exponential function of reaction time between 150 and $500 \mathrm{~ms}$ after the go signal. To prevent the animals from learning the exact timing of the go signal, the time between target onset and the go signal was a semirandom variable. In $70 \%$ of the trials, this time was fixed at $1400 \mathrm{~ms}$, whereas in the other $30 \%$ of trials, the go time was drawn from a unimodal Weibull distribution delayed by $500 \mathrm{~ms}$ (Janssen and Shadlen, 2005) as follows:

$$
\mathrm{U}(\mathrm{t})=\left\{\begin{array}{l}
3 \alpha(\mathrm{t}-1 / 2)^{2} \mathrm{e}^{-\alpha(\mathrm{t}-1 / 2)^{3}} \text { for } \mathrm{t}>1 / 2 \\
0 \text { Otherwise }
\end{array}\right.
$$

During both training and experimental sessions, the subject had to keep both hands in the rest position on a plastic bar in front of the animal. The positions of both hands were monitored using infrared laser beams, which were interrupted when the hands were positioned on the plastic bar. Saccade trials in which the laser beam was no longer interrupted by the hands were aborted.

Arm. During the Arm task, four gray go cues and a blue target appeared (Fig. $1 B$ ) in exactly the same configuration as during the Sacc task. The color of the target (blue, rather than green) indicated to the monkey to maintain fixation in the center of the screen, and to respond to the go signal (i.e., the luminance increase in one of the four go cues) by moving the hand ipsilateral to the target. Until the go cue appeared, the animal had to position both hands on the resting bar. A change in hand positions was detected by interruption of two vertically positioned infrared laser beams (one for each hand; Fig. 1E). When the go cue appeared, the animal had to briefly retract the ipsilateral hand while maintaining the contralateral hand in its start position. The hand had to be retracted toward the body over a distance of minimally $2 \mathrm{~cm}$ to be detected by the infrared laser beam. Note that the exact speed, amplitude, and end position of the arm movement were not measured in this setup. Although the monkeys had to use the hand corresponding to the hemifield in which the target appeared, they did not have to indicate the exact position of the target within this hemifield (e.g., by pointing). This was different in the Sacc task, in which the animals had to make an eye movement toward the target. Therefore, whereas the saccades during Sacc were aimed at precise target locations within a hemifield, the arms were not aimed toward precise target locations during Arm- only toward the hemifield corresponding to the target location. Note, however, that during both Sacc and Arm, the same go cues had to be detected and the target color had to be discriminated, requiring a similarly sized attentional field. After the hand movement, monkeys had to fixate upon the central fixation point for another $250 \mathrm{~ms}$ to obtain the reward. Target and go cues were equal in size $\left(0.27^{\circ}\right)$ and luminance $\left(6 \mathrm{~cd} / \mathrm{m}^{2}\right)$. Stimulus and timing parameters (except for the color of the target) were identical to the ones used in the Sacc. Note that during both training and experimental sessions, the hand positions were also videomonitored to check online that the animals were not making small undesired hand movements that could not be detected by the infrared beam.

Fix. As a baseline condition, we used a Fix task with multiple peripheral dots (Fig. 1C). The visual configuration of the Fix task was matched (in size, luminance, and position of the peripheral dots) to the visually guided saccade and arm tasks. Therefore, in the Fix task, five gray dots were used. The absence of a green or blue target, together with the lack of a go signal, indicated to the animal to maintain fixation until the end of the trial, after which the reward was obtained. Timing parameters were equal for all tasks except for the go time, which was fixed at $1400 \mathrm{~ms}$ for the two saccade and Arm tasks (in 70\% of trials) and at $1700 \mathrm{~ms}$ in $70 \%$ of the passive fixation trials to compensate for differences in reaction time (Arm: Monkey U: 470 ms, Monkey R: 398 ms, Sacc: Monkey U: 373 ms, Monkey R: $263 \mathrm{~ms}$ ). In the remaining 30\% of the fixation trials, the stimulus presentation time was a random variable drawn from a unimodal Weibull distribution (see equation) delayed by $800 \mathrm{~ms}$ (compared with $500 \mathrm{~ms}$ in the Arm and Sacc tasks). The subjects had to keep their hands positioned in the rest position; fixation trials in which the animals made hand movements were aborted. Similarly, trials in which saccades were made were aborted.

Control experiments. To control for any interference effect of the Sacc task upon the Arm task, we performed a separate fMRI experiment (control Experiment 1; Monkey U) with only the Arm and Fix task before the animal had been trained on the Sacc task. Furthermore, we included another Fix task without peripheral dots (Fix0), but with the same timing and reward parameters described above.

For similar purposes, two additional animals now naive to the Arm task were trained to switch between Sacc and two variants of the aforementioned Fix task: one with (Fix1) and one without (Fix0) a peripheral dot (control Experiment 2). During the Sacc task, which was slightly different from that of the main experiment, a green target appeared randomly in one of the four quadrants with no additional peripheral dots. The animal had to maintain fixation until the central fixation point dimmed, which served as the go signal to saccade toward the peripheral target. During Fixl, the animals had to maintain fixation while one peripheral dot (having the same size and color as the target in the Sacc task) appeared at one of four positions in the same locations as the target in the Sacc task of the main experiment. The color of the fixation point indicated to the animal to saccade or to hold fixation. During Fix0, the animals had to maintain fixation until the end of the trial. In contrast to the main experiment, the random go time was now implemented in all trials and was drawn from a unimodal Weibull distribution delayed by $500 \mathrm{~ms}$ (Janssen and Shadlen, 2005).

\section{Scanning}

The tasks (Sacc, Arm, and Fix in the main experiment, Fig. 1D; Arm, Fix and Fix0 in control Experiment 1; and Sacc, Fix0 and Fix1 in control Experiment 2) were presented to the animals in blocks within an fMRI run. In one cycle, every task was presented once in random order. This cycle was repeated twice in one run. Every block lasted for $40 \mathrm{~s}$ (during which 20 functional volumes were acquired).

Functional images were acquired with a $3.0 \mathrm{~T}$ full-body scanner (TIM Trio; Siemens) using a gradient-echo $\mathrm{T} 2^{\star}$-weighted echoplanar imaging sequence (40 horizontal slices; TR: $2 \mathrm{~s}$; TE: $16 \mathrm{~ms} ; 1.25 \mathrm{~mm}^{3}$ isotropic voxels) with a custom-built eight-channel phased-array receive coil and a saddle-shaped, radial-transmit-only surface coil (Kolster et al., 2009). Before each scanning session, a contrast agent, monocrystalline iron oxide nanoparticle (MION; Sinerem; Laboratoire Guerbet), was injected into the femoral/saphenous vein $(7-11 \mathrm{mg} / \mathrm{kg})$. Use of the contrast agent improved the contrast-to-noise ratio $\sim$ threefold and enhanced spatial selectivity of the MR signal changes relative to blood oxygenation leveldependent (BOLD) measurements (Vanduffel et al., 2001; Leite et al., 2002). Whereas BOLD measurements depend on cerebral blood volume (CBV), blood flow, and oxygen extraction, MION measurements depend only on blood volume. Accordingly, we have inverted the polarity of all signal-change values to account for the difference between MION CBV and BOLD activation maps. Note that increased brain activation produces a decrease in MR signal in MION CBV maps.

\section{Image preprocessing}

An offline image reconstruction was conducted to overcome problems inherent to monkey body motion in a $3 \mathrm{~T}$ magnetic field. Details of the image reconstruction protocol have been described previously (Kolster et al., 2009). Briefly, the raw EPI images were corrected for lowest-order off-resonance effects and aligned with respect to the gradient-recalledecho reference images before performing a SENSE (sensitivity encoding) image reconstruction. Corrections for higher-order distortions were performed using a nonrigid slice-by-slice distortion correction. 
Event-related analysis

A white square $\left(0.29^{\circ}\right)$, superimposed on the first video frame containing a stimulus (target and go cues in Sacc and Arm; peripheral dots in Fix), appeared in the lower right corner of the otherwise black screen. This square was completely obscured from the monkeys' view, but was detected by an optic cable transferring the signal to a photodiode. The onset of the white square, digitized and processed at $20 \mathrm{kHz}$ on a digital signal processor (DSP; C6000 series; Texas Instruments), provided the timestamp used to extract the exact timing of every event in each trial.

For the event-related analysis, we included the same number of correct trials (randomly selected) per condition and per run. Median time between the onsets of two consecutive trials was $8.44 \mathrm{~s}( \pm 0.08$ SEM) across runs. Data were analyzed conform rapid event-related fMRI designs similar to previous monkey studies (Leite and Mandeville, 2006; Popivanov et al., 2012; Premereur et al., 2013) and human studies (Burock et al., 1998; Dale, 1999).

\section{Volume-based data analysis}

Data were analyzed in an event-related fashion using statistical parametric mapping (SPM5) and BrainMatch software based on a fixed-effects general linear model. Realignment parameters were included as covariates of no interest to remove brain motion artifacts. Note that the head of the animals was fixed, which largely reduced brain motion and susceptibility artifacts induced by arm movements. Small leftover motion artifacts were removed using the aforementioned realignment parameters as covariates of no interest (see also Nelissen and Vanduffel, 2011). To exclude the possibility of any influence arising from the amount or frequency of juice rewards, we also included the rate and amount of reward as a covariate of no interest. Each condition was modeled by convolving a gamma function (delta $=0$, tau $=8$, and exponent $=0.3$ ) modeling the MION hemodynamic response function at the onset of every trial over a period of $2 \mathrm{~s}$, reflecting the average length of a trial (Popivanov et al., 2012).

Spatial preprocessing consisted of realignment and rigid coregistration with a template anatomy (M12; Ekstrom et al., 2008). To compensate for echoplanar distortions in the images and for interindividual anatomical differences, the functional images were warped to the template anatomy using nonrigid matching BrainMatch software (Chef d'Hotel et al., 2002). The algorithm computes a dense deformation field by the composition of small displacements minimizing a local correlation criterion. Regularization of the deformation field is obtained by low-pass filtering. The functional volumes were then resliced to $1 \mathrm{~mm}^{3}$ isotropic and smoothed with an isotropic Gaussian kernel (full width at half maximum: $1.5 \mathrm{~mm}$ ). To identify those voxels that were more activated for any given contrast in both subjects, a conjunction analysis of the main experiment was performed between these two animals. Therefore, only voxels that were significantly activated ( $p<0.05$ for each animal family-wise error (FWE) corrected) for each individual animal (fixed effects, group analysis) are shown.

\section{ROI-based analysis}

All ROI analyses and percent signal change (PSC) calculations were performed using MarsBaR version 0.41.1. To investigate the effector preference in the IPS and arcuate sulcus (AS), we calculated the PSC along a path in both sulci at locations spaced $1 \mathrm{~mm}$ apart and their mirror positions in the opposite hemisphere. For the IPS, we defined a path along the ROIs AIP, LIP, and caudal intraparietal area (CIP) in the lateral bank and PEip, MIP, and the ventral part of V6A in the medial bank. For the AS, a path was defined along the ROIs F5a and F5p in the lower bank of the inferior branch of the AS and along FEF and 45b in the upper bank. To calculate significant differences along both paths in the IPS and AS, twotailed paired $t$ tests were performed and significance values were corrected for multiple comparisons (Bonferroni correction: significance threshold divided by number of elements in the path). To calculate significant differences in PSC between conditions, two-tailed paired $t$ tests were performed and significance values were corrected for multiple comparisons (Bonferroni correction; significance threshold divided by number of animals * number of conditions).
Table 1. Average number of correct trials per run per condition

\begin{tabular}{|c|c|c|c|c|c|c|c|c|c|}
\hline & \multicolumn{3}{|l|}{ Arm } & \multicolumn{3}{|l|}{ Sacc } & \multicolumn{3}{|l|}{ Fix } \\
\hline & Left & Right & Total & Left & Right & Total & Left & Right & Total \\
\hline \multicolumn{10}{|l|}{ Monkey R } \\
\hline Average & 9 & 9.4 & 18.37 & 8.77 & 8.2 & 17 & 9 & 8.8 & 17.86 \\
\hline SEM & 0.14 & 0.15 & 0.17 & 0.14 & 0.17 & 0.2 & 0.14 & 0.15 & 0.18 \\
\hline \multicolumn{10}{|l|}{ Monkey U } \\
\hline Average & 8.8 & 8.54 & 17.34 & 7.93 & 7.93 & 15.87 & 10.36 & 10.51 & 20.87 \\
\hline SEM & 0.15 & 0.19 & 0.21 & 0.19 & 0.18 & 0.25 & 0.18 & 0.16 & 0.22 \\
\hline
\end{tabular}

ROIs

Visual ROIs. Visual areas V1, V2, V3, and MT were identified using probabilistic retinotopic mapping data (Janssens et al., 2014).

Motor ROIs. Primary motor cortex F1, in addition to several dorsal and ventral premotor sectors, were defined directly onto the template anatomy (M12). These ROIs included F2 and F7 in dorsal premotor cortex, F4 and three F5 sectors in ventral premotor cortex, F3 (supplementary motor area or SMA proper), and F6 (pre-SMA; Matelli et al., 1985; Nelissen et al., 2005; Nelissen and Vanduffel, 2011). The three F5 sectors correspond to two regions located in the posterior bank of the inferior ramus of the AS (F5p and F5a) and a third region on the convexity posterior to the inferior arcuate ramus (F5c; Nelissen et al., 2005; Gerbella et al., 2011). The F5 ROIs represent the estimated location based on the analysis of its cytoarchitectonic properties (Nelissen et al., 2005).

Somatosensory ROIs. Two ROIs were defined in primary somatosensory cortex S1: one corresponding to areas $3 \mathrm{a}$ and $3 \mathrm{~b}$ located in the posterior bank of the central sulcus and a second one corresponding to areas 1 and 2 located on the posterior central gyrus. In addition, a ROI designated as PEip corresponded to the portion of area 5 in the medial or upper bank of the rostral IPS (Nelissen and Vanduffel, 2011).

Parietal ROIs. In the intraparietal sulcus, areas LIP and AIP were based on previous fMRI studies (Durand et al., 2007) in which the anterior border of LIP was defined using a Sacc task, yielding a saccade responses in LIP but not in the more anteriorly located area AIP. Areas V6A and V6 were identified based on their anatomical locations (Galletti et al., 1999a; Galletti et al., 1999b) and the definition of these areas in Vanduffel et al. (2014), which were based on previous studies (Fattori et al., 2009). Parietal area MIP was defined as the posterior half of the medial wall of the IPS (Colby et al., 1988; Caminiti et al., 1996). Area CIP was defined as the caudal part of the lateral intraparietal sulcus (Tsutsui et al., 2001; Tsutsui et al., 2003).

Frontal ROIs. Frontal regions FEF, 45a, 45b, and 46v were defined on the template brain (M12) using anatomical criteria (Rizzolatti and Luppino, 2001; Nelissen et al., 2005). The 45b ROI represents the estimated location based on the analysis of the cytoarchitectonic patterns (Nelissen et al., 2005).

For calculating the PSC in Figures 6, 7, and 8, only the activated voxels ( $t$-value $>4.9$, consistent with a $p$-value of 0.05 , FWE corrected, for the contrast [Arm vs Sacc or Sacc vs Arm]) in the predefined ROIs were included in the analysis.

\section{Results}

Two macaque monkeys were used in the main fMRI experiment. Within each run, the animals had to perform three tasks that were presented in blocks arranged in pseudorandom order: Sacc with multiple possible go cues (Fig. 1A), Arm with multiple possible go cues (Fig. $1 B$ ), and Fix with multiple peripheral dots. Data were collected during 121 runs $\left(245^{\star} 121\right.$ functional volumes) for Monkey U and 120 runs $\left(245^{\star} 120\right.$ functional volumes) for Monkey R. Importantly, in any given run, all stimuli were presented in virtually identical visual configurations and the attentional conditions in the operant tasks were very similar: the subject had to divide his attention over the four peripheral go cues to detect the go signal (i.e., a luminance change in one of the go cues) and to identify the location of the target. During Sacc, a localized saccade to the target was required, whereas during Arm, only the position 

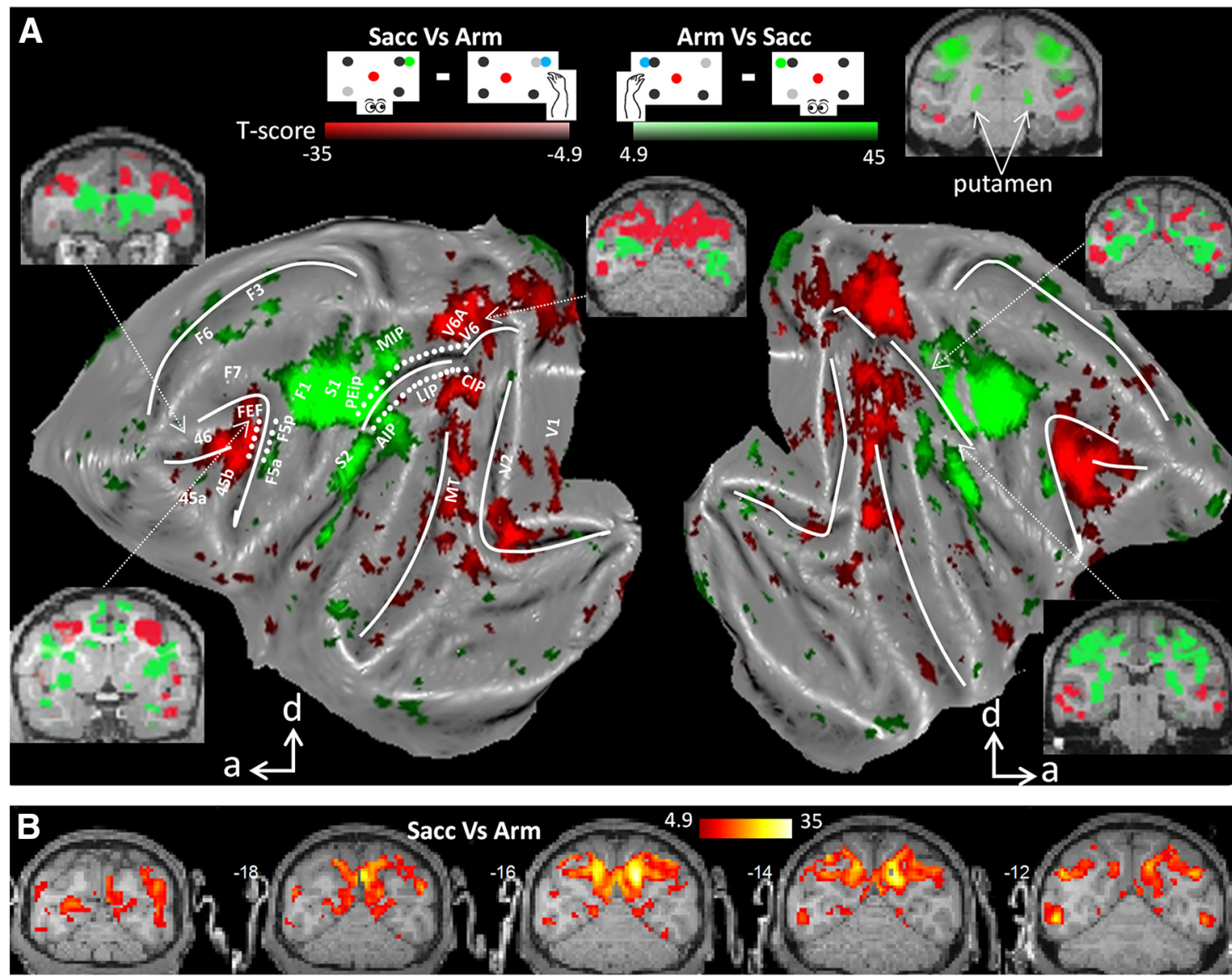

Figure 2. Effector preference. $A$, Flattened cortex showing $t$-score maps representing preference for operant behavior. Conjunction analysis was performed between the two monkeys $(p<0.05$, FWE corrected). $t$-values for the contrast saccade versus arm movement are shown in red; $t$-values for arm movement versus saccade are shown in green. $d$, Dorsal; $a$, anterior. White dots along IPS and AS indicate the path used for analysis in Figure 3. B, Coronal sections centered over posterior parietal cortex showing the results of conjunction analysis across two monkeys $(p<0.05$, FWE corrected, $t$-values for the contrast saccade vs arm movement).

of the target in the left or right hemifield had to be indicated to obtain a reward.

\section{Behavior}

In the main experiment, both monkeys performed slightly better for Arm compared with Sacc (Table 1, 2-way ANOVA with factors subject ${ }^{\star}$ task; main effect for task: $F=42.92$; df $=1 ; p<$ 0.0001; main effect for subject: $F=28.09$; $\mathrm{df}=1 ; p<0.0001$; no significant interaction: $F=0.21, p=0.64$ ), with equal target detection performance for right and left arm movements/saccades (2-way ANOVA with factors task ${ }^{*}$ direction; $\mathrm{df}=1 ; F_{\text {Direction }} \leq 0.57$, $\left.p>0.45 ; F_{\text {Task }}>16.66 ; p<0.001\right)$. The difference in the number of correct trials per task was, however, minimal: number of correct trials for Arm and Sacc: Monkey R: 18.37 and 17, respectively; Monkey U: 17.34 and 15.87, respectively. This was caused by a slightly higher error rate during Sacc compared with Arm (e.g., the saccades were too slow or too fast). Runs in which the animals stopped performing during one of the tasks were removed from the data. Data were analyzed in an event-related fashion including only correct trials, with a total of 686 correct trials per condition for Monkey U and 740 for Monkey R.

Cortical networks preferentially activated by saccades or arm movements

To identify cortical areas displaying increased activity for either type of operant behavior (Arm or Sacc), we contrasted the fMRI activity during the Sacc task with activity during Arm trials and vice versa, as was done in the human fMRI study by Levy et al. (2007). Figure 2 shows all areas (conjunction analysis across subjects, $p<0.05$, FWE corrected) that were significantly more activated during Sacc compared with Arm (red color code) or vice versa (green color code). The conjunction analysis was used to identify those voxels that were more activated for Sacc compared with Arm (or vice versa) in each of the two subjects. In macaque area FEF along the rostral bank and fundus of the AS, saccades evoked significantly stronger fMRI activity than arm movements. Similarly, in comparing Sacc versus Arm, we obtained increased activation levels in prefrontal areas 45 and 46; parietal areas LIP and CIP; occipitoparietal areas V6 and the ventral part of V6A (see also Fig. $2 B$ for coronal sections); motor area F7 (supplementary eye fields); and visual areas V1, V2, V3, V3A, V4, MT, and FST. Therefore, saccades, relative to arm movements, caused increased activations along a parietofrontal network that has been implicated in saccade planning and execution (Nobre et al., 2000; Corbetta and Shulman, 2002; Koyama et al., 2004; Baker et al., 2006). The increased fMRI activations in early visual cortex were likely caused by the "sweep" of the stimuli over the retina elicited by the movement of the eyes while the stimuli remained static on the screen until the saccade was finished and the monkey obtained a reward (Koyama et al., 2004; Baker et al., 2006; Levy et al., 2007). No subcortical activations were found in comparing Sacc versus Arm. 

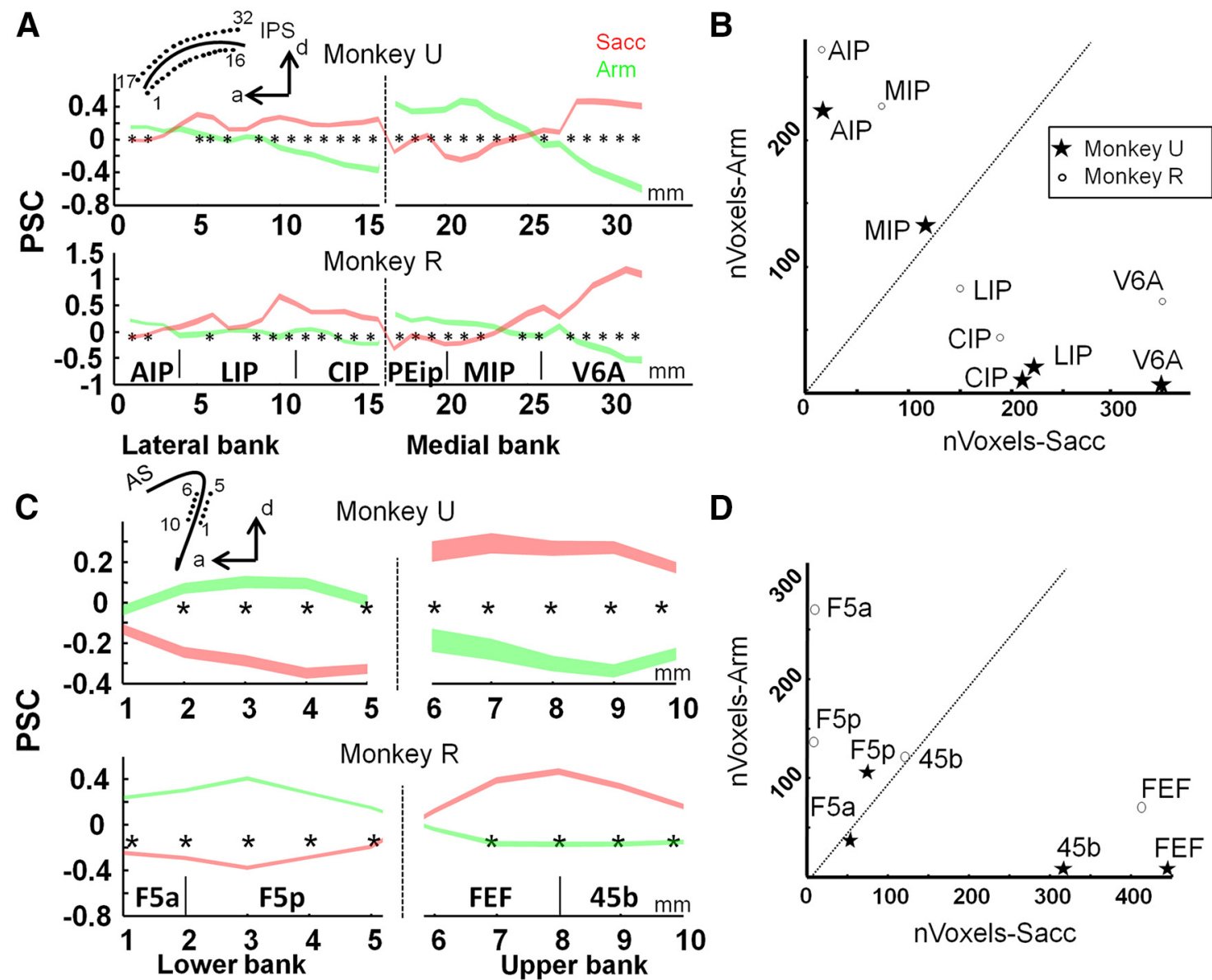

Figure 3. Percent signal change for Arm and Sacc in the intraparietal and arcuate sulcus. $\boldsymbol{A}$, PSC along IPS. PSC was calculated during Sacc (red) and Arm (green) in a path along medial and lateral banks of the IPS (see inset) for each monkey separately. Zero-baseline is the average PSC across all conditions. Figure shows average PSC \pm SEM. ${ }^{*} p<0.05$, corrected for multiple comparisons. $\boldsymbol{B}$, Number of significant voxels ( $p<0.001$, uncorrected, contrast Arm vs Sacc) preferring Arm vs number of significant voxels preferring Sacc ( $p<0.001$, uncorrected, contrast Sacc vs Arm). C, PSC along AS. Conventions as in A. D, Number of significant voxels ( $p<0.001$, uncorrected, contrast Arm vs Sacc) preferring Arm vs number of significant voxels preferring Sacc ( $p<0.001$, uncorrected, contrast Sacc vs Arm).

We also contrasted the fMRI activity during the Arm task with activity during Sacc trials and found significantly higher Armrelated fMRI activity for both animals (conjunction analysis, $p<$ 0.05 , FWE corrected) in motor areas F1, F3 (supplementary motor area, SMA), and F6; area F5 in ventral premotor cortex; somatosensory areas S1 (Brodmann areas $3 \mathrm{a}$ and $3 \mathrm{~b}$ and 1 and 2) and S2; and parietal areas MIP and AIP, all of which have been implicated in grasping or reaching (Mountcastle et al., 1975; Gallese et al., 1994; Snyder et al., 1997; Murata et al., 2000; Andersen and Buneo, 2002; Calton et al., 2002; Nelissen and Vanduffel, 2011). Finally, planning and executing an arm movement compared with a saccade enhanced activity in the putamen (Fig. $2 \mathrm{~A}$, inset), consistent with its role as part of a sensorimotor circuit (Alexander et al., 1990). It needs to be noted that, although no explicit grasping component was required in our Arm task, the animal did have to reposition its hand upon the resting bar at the end of the trial. We did not distinguish between leftward and rightward movements, so increased Arm-induced activations were found in both hemispheres.

To further investigate the effector preference in PPC, we calculated the PSC along a path through the medial and lateral bank of the IPS (32 white dots in left hemisphere in Fig. 2, $1 \mathrm{~mm}$ spacing; mirrored positions were used for right hemisphere). The data are averaged across hemispheres and the average PSC of the three task conditions (Arm, Sacc, and Fix) along the entire path was considered zero baseline. The results in Figure 3, $A$ and $B$, show increased activity in LIP, CIP (middle and posterior caudal part of lateral bank of the IPS), and V6A during Sacc compared with Arm for both animals (paired two-tailed $t$ tests, $p<0.05$, corrected for multiple comparisons). Conversely, the PSC was higher during Arm compared with Sacc in the anterior part of the lateral bank of the IPS (AIP) and in the posterior part of the medial bank of the IPS (MIP). Furthermore, similar to Levy et al. (2007), we calculated the number of voxels significantly preferring Arm (contrast Arm vs Sacc, $p<0.001$, uncorrected) or Sacc (contrast Sacc vs Arm, $p<0.001$, uncorrected) for parietal ROIs. Figure $3 B$ shows that areas AIP and MIP contained more voxels preferring Arm, whereas a greater volume of areas LIP, CIP, and V6A preferred Sacc over Arm in both animals.

We also defined a path in the upper and lower bank of the inferior ramus of the AS (10 white dots in left hemisphere in Fig. 2, $1 \mathrm{~mm}$ spacing) and calculated the PSC for every point along these paths. Figure $3 C$ shows a clear preference for Arm compared with Sacc for both animals in the lower bank of the inferior ramus of the AS (area F5), whereas the upper bank (areas FEF and 45b) displayed a clear preference for Sacc compared with Arm. Furthermore, more voxels in prefrontal areas FEF and 45b preferred saccades compared with arm movements (Fig. 3D), whereas premotor area F5 contains more voxels preferring Arm 

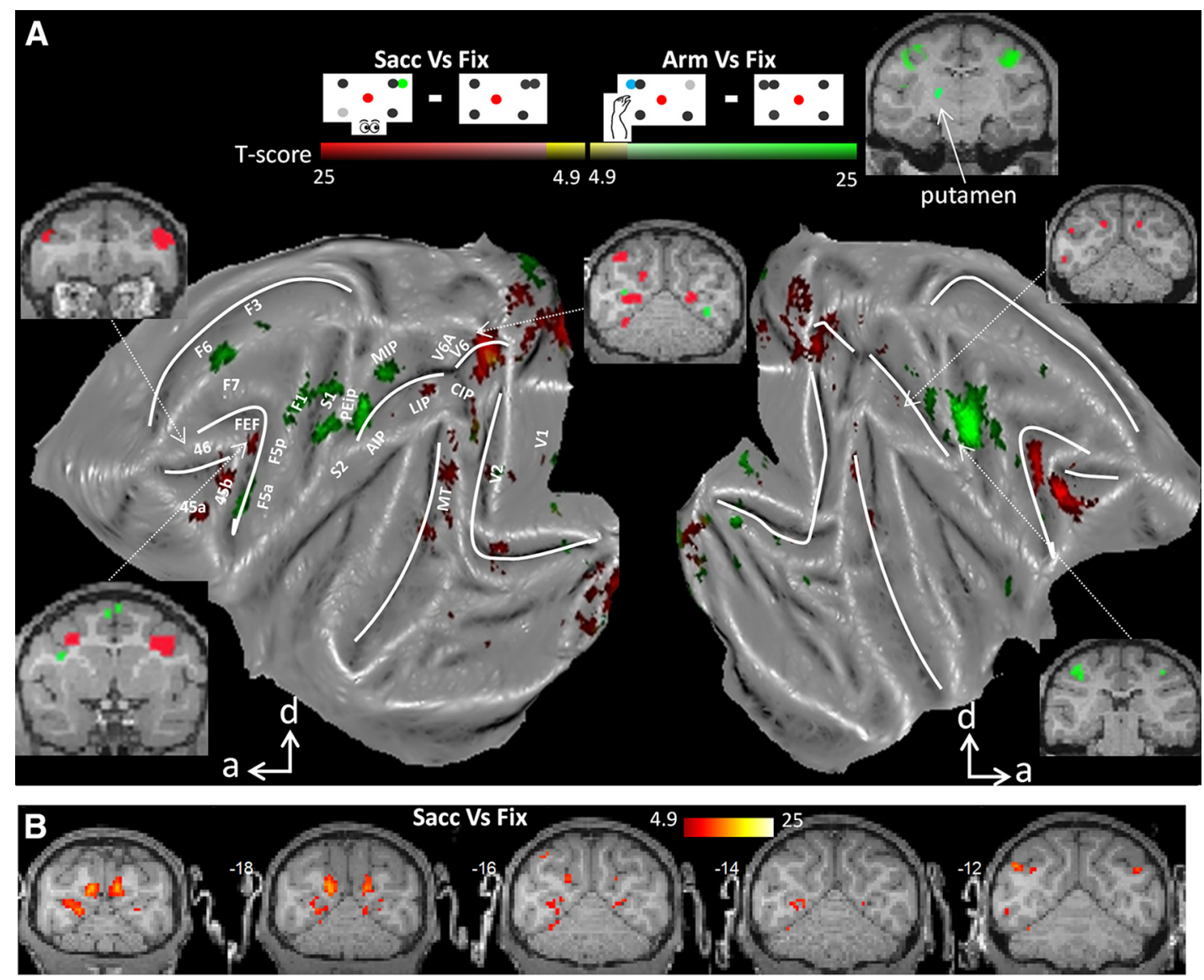

Figure 4. Effector specificity. A, Flattened cortex showing $t$-score maps representing effector specificity. A conjunction analysis was performed between the two monkeys $(p<0.05$, FWE corrected). $t$-values for the contrast saccade versus fixation are shown in red; $t$-values for arm movements versus fixation are shown in green. Overlap is shown in yellow. $\boldsymbol{B}$, Coronal sections centered over posterior parietal cortex with contrast saccade versus fixation ( $t$-score maps, $p<0.05$, FWE corrected).

compared with Sacc (number of significant voxels per ROI; $t$-value $\geq 3.1: p<0.001$ uncorrected).

Similar to previous studies (Medendorp et al., 2005), we compared arm movements to the right versus left and found increased activations in the left hemisphere in the same areas preferring arm movements over saccades (data not shown): area F5(a and p), AIP, MIP, F1, S1, and S2. In comparing saccades to the right versus left, however, we did not obtain increased activations in contralateral parietofrontal areas, most likely due to the fact that the animals always have to reposition their eyes back to the fixation point.

In summary, two distinct networks showed a clear preference for either arm movements or saccades under equivalent attentional conditions. The previous analysis, however, does not reveal whether these networks are solely activated during the preferred type of operant behavior. Either network could still show increased activity during the nonpreferred type of operant behavior compared with a fixation-only baseline.

\section{Effector specificity in the saccade and arm movement networks}

To determine the effector specificities of both networks, we contrasted the fMRI activation patterns evoked by either type of operant behavior separately to the activation pattern during the baseline fixation condition. Figure 4 shows all areas that were significantly more activated during Sacc compared with Fix (conjunction analysis across subjects, $p<0.05$, FWE corrected, red color code). Similar to the previous analysis, we obtained in- creased saccade-related activation in prefrontal areas FEF, 45 and 46, in part of parietal area LIP (posterior LIP), in V6, in area MT, and in (parts of) early visual areas V1, V2, V3, and V3A (see also Fig. $4 B$ for coronal sections). Conversely, comparing Arm versus Fix (green color code), we obtained significantly increased fMRI activation levels in parietal area MIP, motor areas F1 and F3, somatosensory area $\mathrm{S} 1$, premotor area F5a, and putamen (Fig. 4, inset). Note that the activations in Figure 2 (Arm vs Sacc and vice versa) are substantially more widespread than those in Figure 4 (Arm vs Fix and Sacc vs Fix), suggesting a suppression of activity in the respective control condition relative to fixation baseline. Importantly, we did not observe any areas showing increased fMRI activation for both types of operant behavior (compared with Fix; overlap would be shown in yellow color code), which illustrates that the networks activated by saccades and arm movements were mutually exclusive.

\section{Decreased activity in saccade and arm movement networks for the nonpreferred type of movement}

Thus far, we have shown that prefrontal areas display a clear preference and even specificity for Sacc compared with Arm in the individual subjects. As already suggested by the comparison between Figures 2 and 4 (see above), areas activated during Sacc may be deactivated relative to fixation only, during Arm, or vice versa. This holds true for areas FEF and 45, which were significantly deactivated while the animals performed arm movements compared with the baseline fixation condition (Fig. 5, cf. Fix vs Arm, conjunction analysis, $p<0.05$ FWE corrected). Indeed, by 


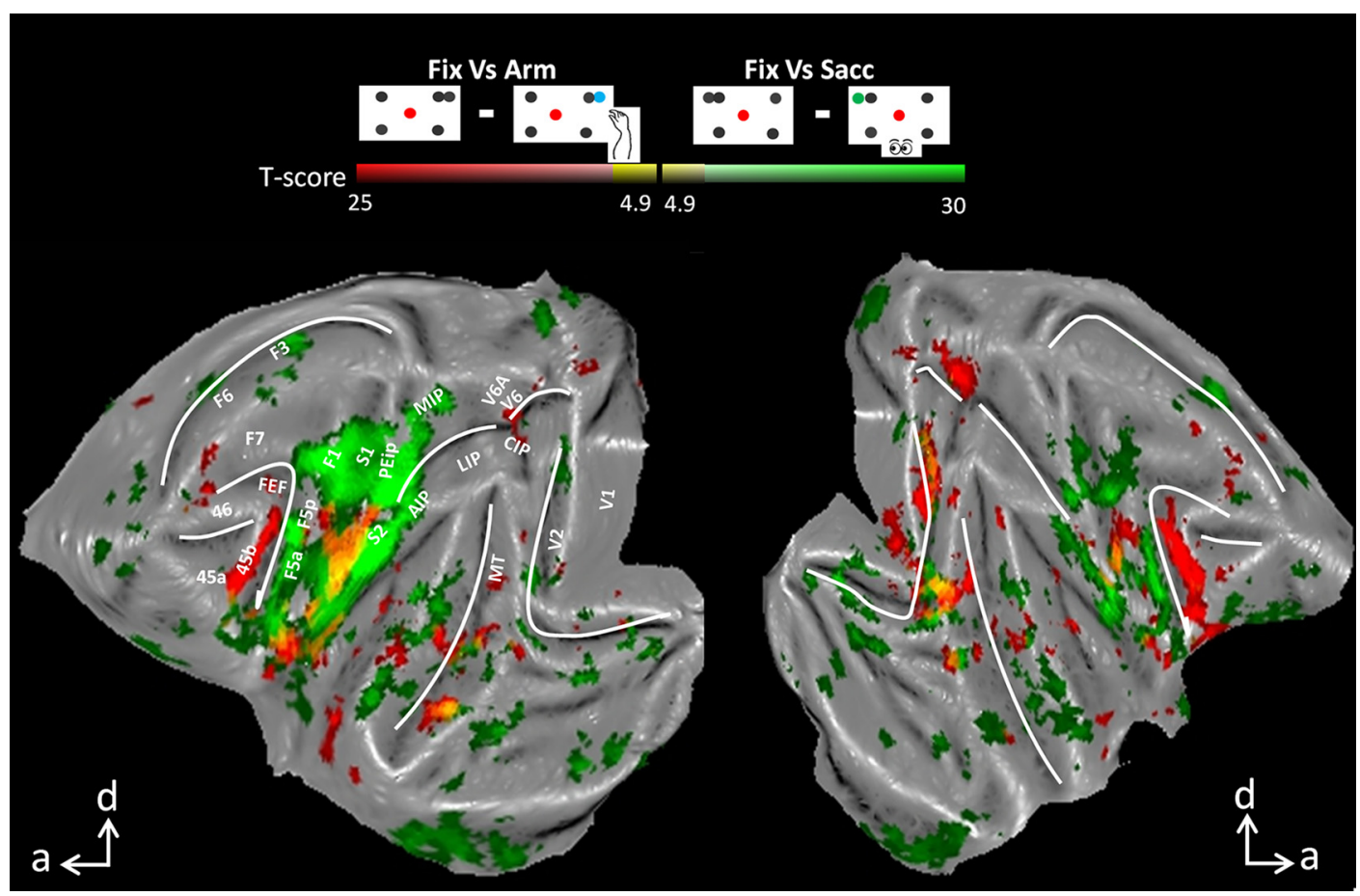

Figure 5. Flattened cortex showing $t$-score maps representing decreased activation during operant behavior. A conjunction analysis was performed between the two monkeys $(p<0.05$, FWE corrected). $t$-values for the contrast fixation versus arm movement are shown in red; $t$-values for fixation versus saccade are shown in green. Overlap is shown in yellow.

comparing the PSC in activated voxels (for the contrast Arm vs Sacc or Sacc vs Arm as in Fig. 2) in areas FEF, 45a and 45b (left and right hemisphere combined), we observed for the individual monkeys a significant decrease in $\mathrm{fMRI}$ activity during Arm compared with Fix (paired $t$ tests, $p<0.05$, corrected for multiple comparisons, Fig. $6 A$, baseline is the average PSC over all conditions). Therefore, during Arm, activity levels decrease (compared with Fix) in prefrontal areas typically preferring saccades over arm movements. Similar levels of deactivation were found (in both hemispheres) within small patches along the STS and in visual cortex (Fig. 5, red patches), in area V6 along the parietooccipital sulcus, but not along the IPS. In control Experiment 1, we presented the fixation condition without peripheral dots to Monkey $\mathrm{U}$, and similar decreases in activity were found comparing Arm with the latter fixation condition (Fig. 7B).

Note that all PSC calculations in Figure 6 were based on voxels activated by the contrasts Arm versus Sacc or Sacc versus Arm. Similar results were obtained using voxels activated by the contrasts Arm versus Fix or Sacc versus Fix (i.e., all activated voxels in Fig. 4), although these activations were substantially less widespread. In this experiment, we also obtained a significant increase in PSC in Sacc compared with Fix for both animals in FEF, 45a and 45b, and a decrease in PSC during Arm compared with Fix for both monkeys in areas FEF and 45b and for Monkey R in 45a (paired $t$ tests, $p<0.05$, corrected for multiple comparisons; data not shown).

Similar to the deactivation in prefrontal areas during Arm, we obtained a decrease in activity during saccades compared with fixation in the key ROIs of the Arm network (Fig. 5, contrast Fix vs Sacc, green color code, $p<0.05$, FWE corrected). Both hemispheres displayed decreased fMRI activity during Sacc versus Fix in motor area F1, somatosensory areas $\mathrm{S} 1$ (3a/3b en $1 / 2)$ and S2, and premotor areas F5a and F5p (see also Fig. 6 B for PSC). Note that a significant decrease in parietal areas MIP and AIP was obtained only in the left hemisphere. Similar levels of deactivation were found (in both hemispheres) in small patches along the
STS and in early visual areas (Fig. 5, red patches). Note also that the PSC increases significantly during Arm compared with Fix for both animals in F1 and S1. The decrease in PSC in F5a for Monkey U during Arm compared with Fix was due to the slightly more anterior activations during Arm versus Fix compared with Arm versus Sacc (cf. Figs. 2, 4).

\section{Control Experiment 1}

Thus far, we have described a parietofrontal network including areas LIP, FEF, 45 and 46, which is specifically activated during Sacc, with areas FEF and 45 deactivated during the performance of the Arm tasks. The decrease in activation during one operant behavior relative to the other could be a consequence of our specific task-switching paradigm or training sequence whereby the monkey actively suppresses the unwanted operant behavior during the performance of the required behavior. To exclude this possible explanation, we analyzed another fMRI dataset acquired in Monkey U before training on the Sacc task. Therefore, Monkey $\mathrm{U}$ was only alternating between Arm and Fix at this point in the experimental protocol and had used only arm movements as an operant behavior, with no prior saccadic experience in the context of an experimental task.

Data were collected in three sessions comprising 87 runs. On average, 17.41 correct Arm-trials (SE 0.34) and 23.26 correct Fix trials (SE 0.18) were performed per run. A fixation condition without distractors was included (on average 24.13 correct trials per run, SE 0.15).

Similar to the main experiment (Figs. 4,5), we obtained increased activation during Arm movements compared with fixation in areas F5, F1, S1, and MIP and a decrease in fMRI activation in prefrontal areas $45, \mathrm{FEF}$, and 46 . Note that we found a decrease in activation throughout the entire cortex, including parietal areas LIP and CIP, parieto-occipital areas V6(A), and areas along the STS (Fig. 7A). 
Figure 7, $B$ and $C$, shows the PSC calculated in the same voxels as those used in Figure 6 (voxels activated by the contrast Arm vs Sacc or Sacc vs Arm as shown in Fig. 2). When comparing Arm vs Fix prior training on the Sacc task, we found significantly increased Arm activity in areas F1, S1 (1/2 and 3a3b), PEip, and F5a (Fig. $7 C$; paired $t$ tests, $p<0.05$, corrected for multiple comparisons). Conversely, in comparing Fix versus Arm, we observed significantly decreased activity in prefrontal areas 45 and FEF (Fig. 7B), similar to the decrease found when animals had to switch between operant behaviors (Fig. 6). Note that, in contrast to the results displayed in Figure 6, the baseline in Figure 7 is a fixation condition without peripheral dots.

\section{Control Experiment 2}

In a final control experiment, two other monkeys were scanned during Sacc without prior training in an arm movement task. Data were collected over 36 runs for Monkey K ( 4 sessions, average number of correct trials per run: Sacc: $23.39 \pm 0.75$; Fix1: $34.83 \pm 0.47$; Fix0: $34.91 \pm 0.43$ ) and 46 runs for Monkey S ( 3 sessions, average number of correct trials per run: Sacc: $25.68 \pm 0.58$; Fix1: $36.21 \pm 0.29$; Fix0: $36.40 \pm 0.32$ ). As in Figure 6, a significant increase in PSC (calculated in the same voxels of the template space as used for Figs. 6, 7) was obtained for prefrontal areas FEF, 45a and 45b (Fig. $8 A, B$ ). Furthermore, for both animals, we found significantly decreased activity (compared with the fixation baseline without peripheral dots) in the Arm network: F1, S1, PEip, and F5p (Fig. 8A,C). Together, these results suggest that the observed decreased activity in the Arm or Sacc network during the performance of saccades or arm movements, respectively, was not induced by the training sequence or by the rapid switching between two effectors within a given run.

\section{Discussion}

Monkeys were scanned while alternating between the Fix, Sacc, and Arm tasks. We found a frontoparietal network containing areas V6, V6A, LIP, CIP, FEF, 45a, 45b, and 46 preferentially activated with saccades instead of arm movements as operant behavior. A complementary cortical network containing areas MIP, PEip, AIP, S1, S2, F1, F3, F5, and F6 was activated when arm movements were used as operant. Interestingly, several cortical areas in both functional networks were deactivated by the nonpreferred type of operant.

\section{Correspondence fMRI with electrophysiological results in monkeys}

Consistent with monkey electrophysiology, we found a preference for arm movements in the medial bank of the IPS (MIP),
FEF
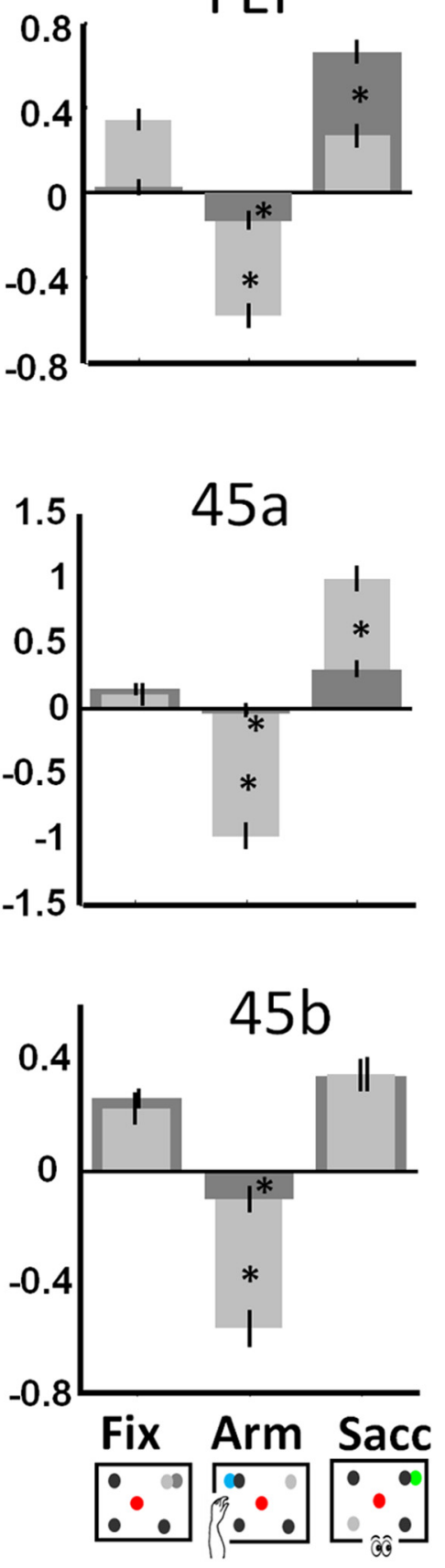

B

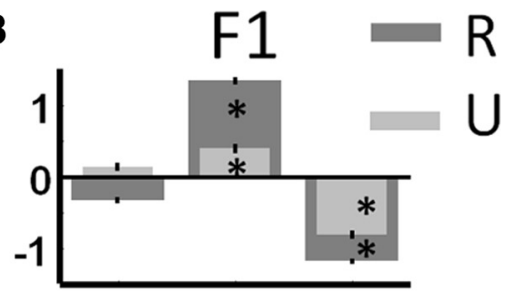

$3 a-3 b$

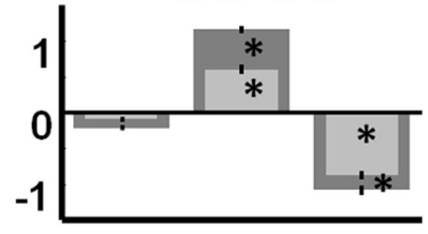

$1 / 2$

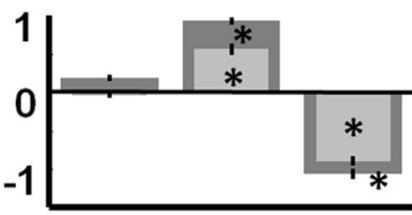

PEip
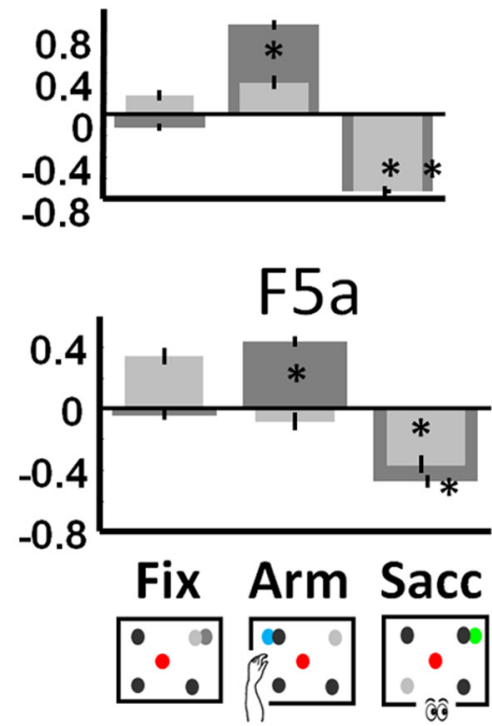

Figure 6. Percent signal change per condition. Baseline is average PSC over conditions. ${ }^{*} p<0.05$ corrected for multiple comparisons (compared with Fix). Data for Monkey R are shown in dark gray, data for Monkey U in light gray. Black bars represent the SEM across runs. $A$, Sacc network. $B$, Arm network.

and a saccade preference in the lateral bank (LIP, CIP; Gnadt and Andersen, 1988; Duhamel et al., 1992; Colby et al., 1996; Snyder et al., 1997; Platt and Glimcher, 1998; Calton et al., 2002; Pesaran et al., 2002; Scherberger et al., 2005). Both MIP and LIP, however, also contain some neurons responding to the nonpreferred type of operant (Snyder et al., 1997; Colby and Goldberg, 1999; Eskandar and Assad, 1999; Gottlieb and Goldberg, 1999). Due to the limited spatial resolution of fMRI, the response of small neuronal populations responding to the nonpreferred effector can easily remain unnoticed. Because fMRI provides a relatively good estimate of the overall population selectivity (Tsao et al., 2006; Popivanov et al., 2014; for review, see Vanduffel et al., 2014), 

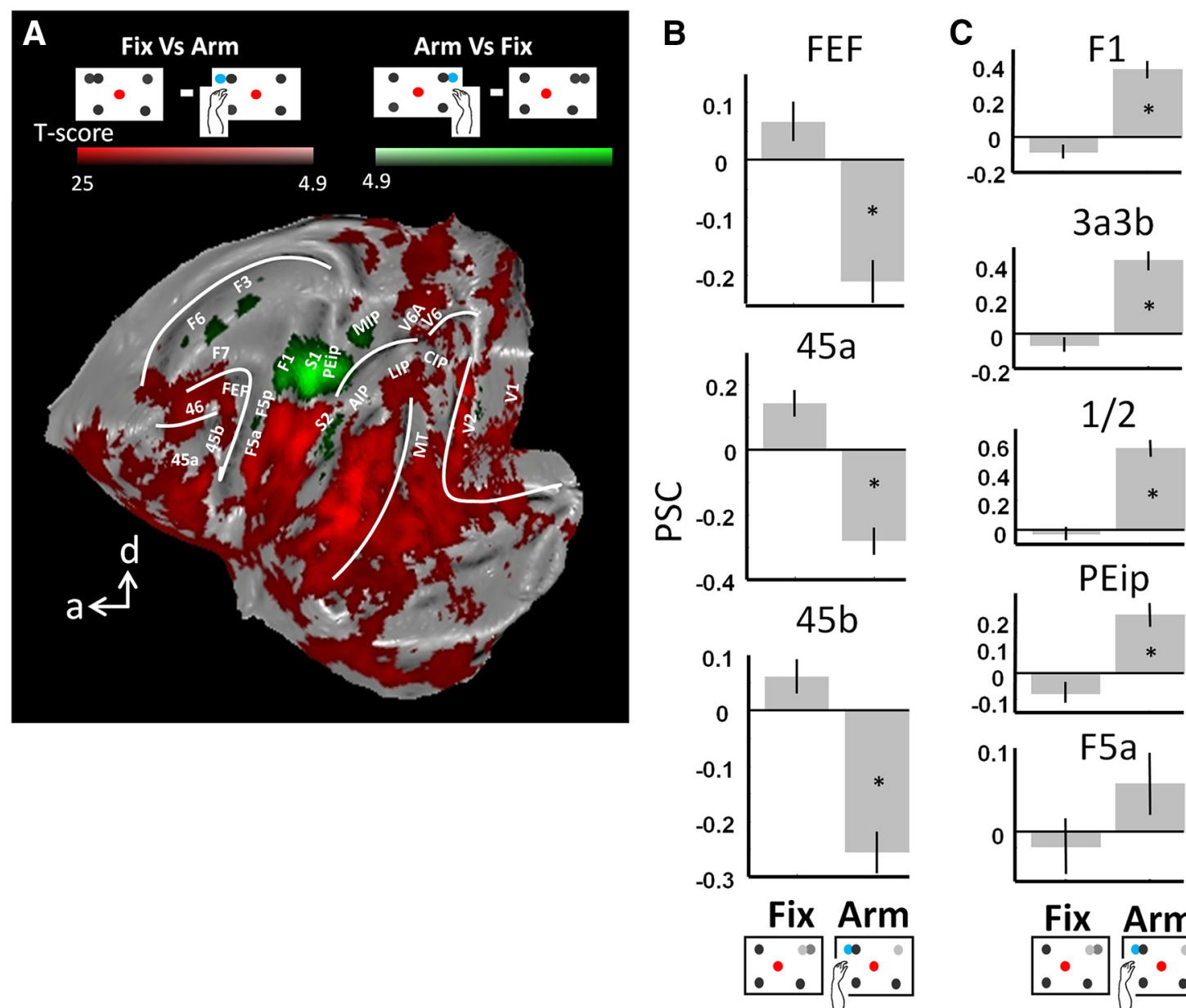

\section{$3 a 3 b$}
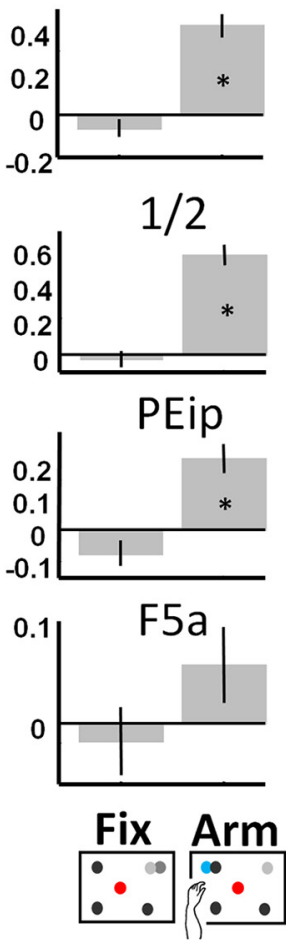

Figure 7. Control Experiment 1.A, Flattened cortex (left hemisphere) showing $t$-score maps representing the contrast arm movement versus fixation (green) and fixation versus arm movement (red) for Monkey U ( $p<0.05$, FWE corrected). B, C, Percent signal change per condition for Monkey U during Arm. Baseline is PSC during fixation without distractors. ${ }^{*} p<0.05$ corrected for multiple comparisons (compared with baseline). Black bars represent the SEM across runs. B, Sacc network. C, Arm network.

however, the present data are consistent with the generally accepted view of a network of parietal areas in the monkey preferring either saccades or arm movements.

The arm movement preference in medial IPS was limited to MIP, although the parietal reach region (PRR) also includes V6A (Snyder et al., 2000; Fattori et al., 2001; Fattori et al., 2004), containing 78\% of reach-related cells (Fattori et al., 2005). Contrary to visual area V6 (Galletti et al., 1999a), V6A is typically described as a visuomotor area with $11 \%$ saccadic eye movement neurons (Kutz et al., 2003) and 48\% cells showing postsaccadic responses (Nakamura et al., 1999). It is noteworthy that previous studies of V6A typically used visually guided grasping or reaching tasks in which the animals had to grasp an object or to reach toward a specific point in space (Bosco et al., 2010; Fattori et al., 2010). Therefore, the lack of a precisely localized reaching movement in the present experiment may explain the lack of arm movement activity over the entire region typically denoted as PRR. In fact, the absence of a precise, visually guided reaching movement in the present study might also explain the unexpected lack of increased fMRI activity during Arm in V6A, F2, and superior parietal lobe areas PE and PEc (Crammond and Kalaska, 2000; Ferraina et al., 2001; Raos et al., 2003; Fattori et al., 2005; Breveglieri et al., 2006; Batista et al., 2007; Ferraina et al., 2009).

Furthermore, V6A responds to moving stimuli in peripersonal space (Galletti et al., 1999b), so the lack of visual feedback might contribute to the lack of V6A activation during Arm (see also Hagler et al., 2007). However, V6A activations were also observed in the absence of visual feedback (Fattori et al., 2001; Fattori et al., 2005; Bosco et al., 2010; Hadjidimitrakis et al., 2014a; Hadjidimitrakis et al., 2014b). Finally, previous single cell research found area V6A to be activated by spatial, directional shifts of the spotlight of attention (Galletti et al., 2010). Such an attentional shift is certainly present during our Sacc task, but is likely to be less pronounced during the Arm task because the directional requirements of this task are weaker. The lack of activation in V6A during Arm could therefore also be due to a weaker attentional spatial shift signal.

Similar to the effector preference in PPC, our study showed also a clear preference for saccades in FEF, which is in agreement with many electrophysiological studies (Bruce et al., 1985; Tehovnik et al., 2000; Schall, 2002; Noudoost et al., 2014) and corroborates a single-cell study specifically comparing neuronal activity in this same area during visually guided saccades and reaches (Lawrence and Snyder, 2006).

In addition to the saccade selectivity of FEF and area 45, our results showed markedly decreased activity in these areas during arm movements compared with a fixation-only baseline. This decreased arm-movement-related activity cannot be attributed to training history or rapid task switching because it was also observed in a subject trained only in the Arm task before learning the Sacc task. Moreover, the suppressed fMRI activity in FEF and area 45 cannot be due to the mere inhibition of arm movements 

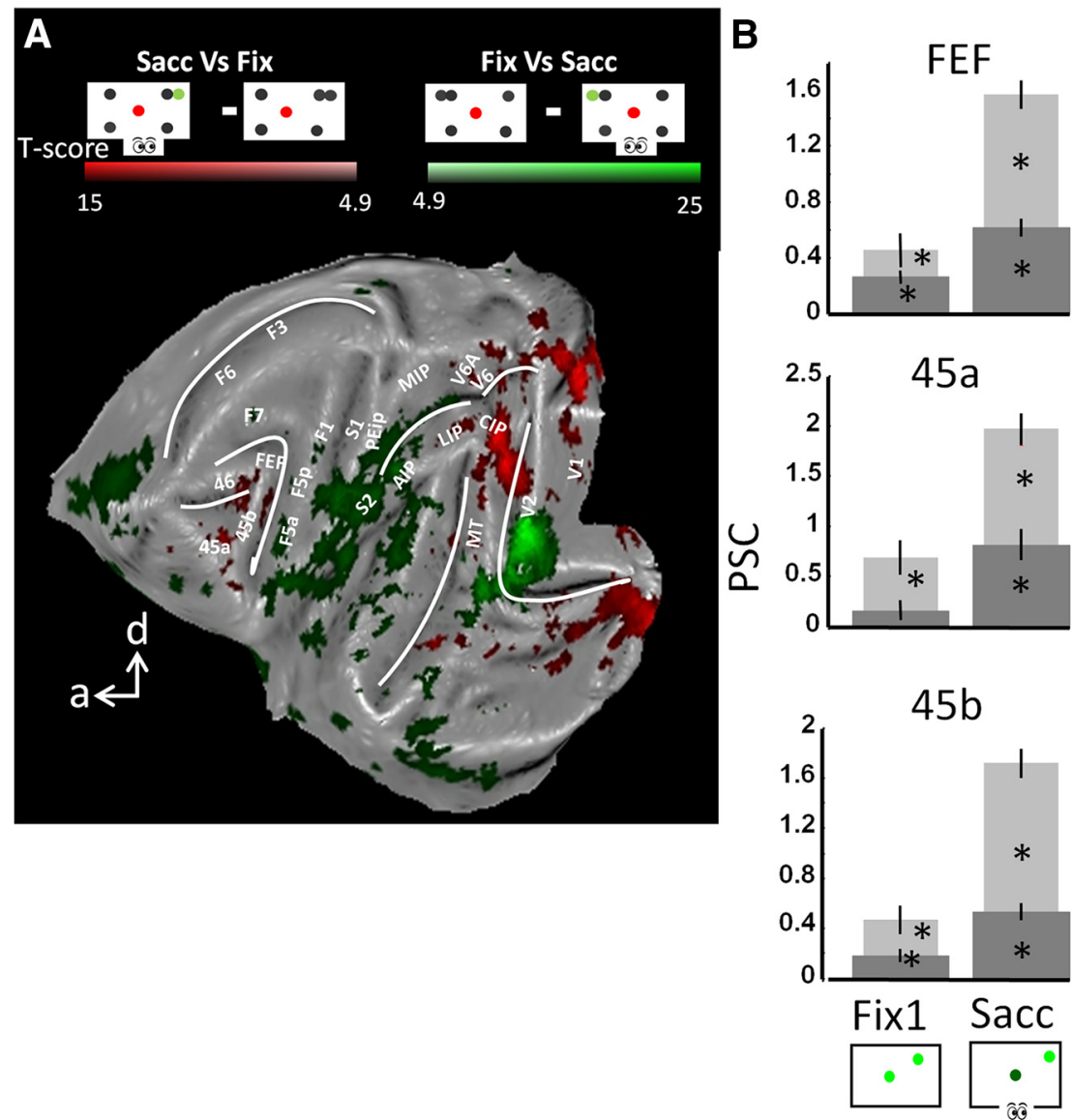
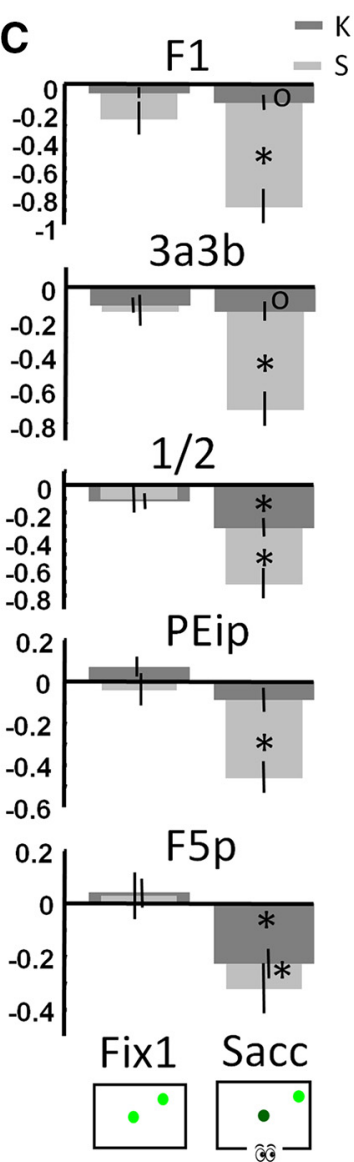

Figure 8. Control Experiment 2. A, Flattened cortex showing $t$-score maps for a conjunction analysis between two monkeys (Monkeys $K$ and $S, p<0.05$, FWE corrected). The contrasts saccade versus fixation (red) and fixation versus saccade (green) are shown. B, C, Percent signal change per condition for Monkeys Kand S during Sacc. Baseline is PSC during fixation without distractors. ${ }^{*} p<$ 0.05, corrected for multiple comparisons; ${ }^{\circ} p<0.01$, uncorrected (compared with baseline). Black bars represent the SEM across runs. $\boldsymbol{B}$, Sacc network. $\boldsymbol{C}$, Arm network.

because the animals also had to refrain from making arm movements during the baseline fixation condition. Decreased FEF activity during arm movements is consistent with a previous singlecell study (Thompson et al., 2005) showing that FEF movement neurons, responding only when making a saccade, are suppressed during a manual response in the context of a pop-out search task. Based on these data, Thompson et al. (2005) suggested that spatial attention signals in FEF can be independent of explicit saccade command signals in the FEF. Furthermore, because the FEF was profoundly deactivated during the Arm task with similar attentional requirements as the Sacc, it is tempting to speculate that the same attentional signals (the go cue corresponds to a pop-out signal in both Arm and Sacc) may also be linked to functional networks not necessarily including the FEF (i.e., in regions of the Arm network). Further support for this conjecture, that the same attention signals can be carried by two complementary functional networks, comes from a similar deactivation in substantial portions of the Arm network (primary motor and somatosensory cortex, PEip, and F5a) during the Sacc task. This decrease in saccade-related activity in the Arm network was observed in the main and the control experiment, having very similar attentional demands, but in which the animals were never trained in an operant task requiring arm movements. Therefore, task switching and training history can also not explain the deactivations in the Arm network observed during the Sacc task.

The increased fMRI activations in early visual cortex could be caused by the "sweep" of the moving retinas over the static stim- uli (Koyama et al., 2004; Baker et al., 2006; Levy et al., 2007). Although the increased parietofrontal activation during Sacc could also be due to this sweep, electrophysiology showed that single neurons in these areas respond before the saccade (Goldberg and Bushnell, 1981; Schlag and Schlag-Rey, 1987; Colby et al., 1996). Finally, such sweep-driven activations cannot explain the reduced fMRI activity during Arm because the visual stimuli are matched between the two task conditions except for the color of the target point.

\section{Comparison with human imaging}

Several human imaging studies indicated a large overlap in PPC during saccades and arm/hand movements (Astafiev et al., 2003; Levy et al., 2007; Beurze et al., 2009; Heed et al., 2011). Recent research using a combination of information patterns and activation measures, for example, indicated that rostral PPC does not code single effectors, but rather effector dichotomies of distinct and common representations, which makes the PPC the ideal region for selecting the appropriate movements (Leoné et al., 2014). Effector-specific signals, conversely, have been shown in other magnetoencephalography (Van Der Werf et al., 2008; Van Der Werf et al., 2010) or fMRI studies (Connolly et al., 2003; Medendorp et al., 2005). This resulted in a functional description of human PPC similar to the macaque (Vesia and Crawford, 2012), in which functional homologs for macaque LIP and MIP have been proposed (Connolly et al., 2003; Schluppeck et al., 2005; Hagler et al., 2007). 
Furthermore, contrary to electrophysiological macaque studies, little or no effector selectivity was found in human frontal cortex, including FEF (Astafiev et al., 2003; Connolly et al., 2007; Levy et al., 2007; Hagler et al., 2007) except for ventral FEF (Connolly et al., 2007). Therefore, the observed strong effector preference throughout PPC, and to a lesser extent FEF, is consistent with a number of human studies, including patient and TMS studies (Vesia and Crawford, 2012).

Importantly, our Arm and Sacc task differed in several aspects. Although the eyes were aimed at precise targets, arm movements were not precise because only the hemifield of the target had to be indicated. Although the spatial attention required for detecting go cues and targets is identical in Sacc and Arm trials, the attentional fields may shrink during the execution phases of both tasks. A previous study showed that human IPS and FEF were involved in the planning and execution of both saccades and pointing movements and both areas were also implicated in spatial attention (Astafiev et al., 2003; see also Nobre et al., 2000; Corbetta and Shulman, 2002). Astafiev et al. (2003) even suggested an attentional role that generalizes across response effectors. Therefore, the lack of a precisely aimed spatial arm movement during Arm could, at least in theory, explain why LIP and FEF were only activated during saccades. Similarly, the lack of a precise reaching movement in the current design might not be sufficient to activate PPC for encoding the spatial location of the target (Andersen, 1995). Previous single-cell research, however, showed that, similar to our study, FEF and LIP were more active during saccades compared with equally localized reaches (Snyder et al., 1997; Lawrence and Snyder, 2006).

Our study was the first to compare directly fMRI activations in the macaque brain during saccades versus arm movements. We showed that areas activated during saccades are largely segregated from areas involved in arm movements. More generally, our data showed that areas more directly involved in generating motor output (e.g., FEF, F1) are inhibited by nonpreferred effector types compared with hierarchically lower-level areas (e.g., LIP, MIP). An open, yet to be addressed question concerns the difference in neural substrates processing directional (left vs right) and precisely localized (pointing) operant behaviors.

\section{References}

Alexander GE, Crutcher MD, DeLong MR (1990) Basal gangliathalamocortical circuits: parallel substrates for motor, oculomotor, "prefrontal" and "limbic" functions. Prog Brain Res 85:119-146. Medline

Andersen RA (1995) Encoding of intention and spatial location in the posterior parietal cortex. Cereb Cortex 5:457-469. CrossRef Medline

Andersen RA, Buneo CA (2002) Intentional maps in posterior parietal cortex. Annu Rev Neurosci 25:189-220. CrossRef Medline

Astafiev SV, Shulman GL, Stanley CM, Snyder AZ, Van Essen DC, Corbetta M (2003) Functional organization of human intraparietal and frontal cortex for attending, looking, and pointing. J Neurosci 23:4689-4699. Medline

Baker JT, Patel GH, Corbetta M, Snyder LH (2006) Distribution of activity across the monkey cerebral cortical surface, thalamus and midbrain during rapid, visually guided saccades. Cereb Cortex 16:447-459. Medline

Batista AP, Santhanam G, Yu BM, Ryu SI, Afshar A, Shenoy KV (2007) Reference frames for reach planning in macaque dorsal premotor cortex. J Neurophysiol 98:966-983. CrossRef Medline

Beurze SM, de Lange FP, Toni I, Medendorp WP (2009) Spatial and effector processing in the human parietofrontal network for reaches and saccades. J Neurophysiol 101:3053-3062. CrossRef Medline

Bosco A, Breveglieri R, Chinellato E, Galletti C, Fattori P (2010) Reaching activity in the medial posterior parietal cortex of monkeys is modulated by visual feedback. J Neurosci 30:14773-14785. CrossRef Medline

Breveglieri R, Galletti C, Gamberini M, Passarelli L, Fattori P (2006) Somatosensory cells in area PEc of macaque posterior parietal cortex. J Neurosci 26:3679-3684. CrossRef Medline
Bruce CJ, Goldberg ME, Bushnell MC, Stanton GB (1985) Primate frontal eye fields. II. Physiological and anatomical correlates of electrically evoked eye movements. J Neurophysiol 54:714-734. Medline

Burock MA, Buckner RL, Woldorff MG, Rosen BR, Dale AM (1998) Randomized event-related experimental designs allow for extremely rapid presentation rates using functional MRI. Neuroreport 9:3735-3739. CrossRef Medline

Calton JL, Dickinson AR, Snyder LH (2002) Non-spatial, motor-specific activation in posterior parietal cortex. Nat Neurosci 5:580-588. CrossRef Medline

Caminiti R, Ferraina S, Johnson PB (1996) The sources of visual information to the primate frontal lobe: a novel role for the superior parietal lobule. Cereb Cortex 6:319-328. CrossRef Medline

Chef d'Hotel C, Hermosillo G, Faugeras O (2002) Flows of diffeomorphisms for multimodal image registration. Proc IEEE Int Symp Biomed Imaging 7:753-756

Colby CL, Goldberg ME (1999) Space and attention in parietal cortex. Annu Rev Neurosci 22:319-349. CrossRef Medline

Colby CL, Gattass R, Olson CR, Gross CG (1988) Topographical organization of cortical afferents to extrastriate visual area PO in the macaque: a dual tracer study. J Comp Neurol 269:392-413. CrossRef Medline

Colby CL, Duhamel JR, Goldberg ME (1996) Visual, presaccadic, and cognitive activation of single neurons in monkey lateral intraparietal area. J Neurophysiol 76:2841-2852. Medline

Connolly JD, Andersen RA, Goodale MA (2003) FMRI evidence for a 'parietal reach region' in the human brain. Exp Brain Res 153:140-145. CrossRef Medline

Connolly JD, Goodale MA, Cant JS, Munoz DP (2007) Effector-specific fields for motor preparation in the human frontal cortex. Neuroimage 34:1209-1219. CrossRef Medline

Corbetta M, Shulman GL (2002) Control of goal-directed and stimulusdriven attention in the brain. Nat Rev Neurosci 3:201-215. CrossRef Medline

Crammond DJ, Kalaska JF (2000) Prior information in motor and premotor cortex: activity during the delay period and effect on pre-movement activity. J Neurophysiol 84:986-1005. Medline

Dale AM (1999) Optimal experimental design for event-related fMRI. Hum Brain Mapp 8:109-114. CrossRef Medline

Duhamel JR, Colby CL, Goldberg ME (1992) The updating of the representation of visual space in parietal cortex by intended eye movements. Science 255:90-92. CrossRef Medline

Durand JB, Nelissen K, Joly O, Wardak C, Todd JT, Norman JF, Janssen P, Vanduffel W, Orban GA (2007) Anterior regions of monkey parietal cortex process visual 3D shape. Neuron 55:493-505. CrossRef Medline

Ekstrom LB, Roelfsema PR, Arsenault JT, Bonmassar G, Vanduffel W (2008) Bottom-up dependent gating of frontal signals in early visual cortex. Science 321:414-417. CrossRef Medline

Eskandar EN, Assad JA (1999) Dissociation of visual, motor and predictive signals in parietal cortex during visual guidance. Nat Neurosci 2:88-93. CrossRef Medline

Everling S, Dorris MC, Klein RM, Munoz DP (1999) Role of primate superior colliculus in preparation and execution of anti-saccades and prosaccades. J Neurosci 19:2740-2754. Medline

Fattori P, Gamberini M, Kutz DF, Galletti C (2001) 'Arm-reaching' neurons in the parietal area V6A of the macaque monkey. Eur J Neurosci 13:23092313. CrossRef Medline

Fattori P, Breveglieri R, Amoroso K, Galletti C (2004) Evidence for both reaching and grasping activity in the medial parieto-occipital cortex of the macaque. Eur J Neurosci 20:2457-2466. CrossRef Medline

Fattori P, Kutz DF, Breveglieri R, Marzocchi N, Galletti C (2005) Spatial tuning of reaching activity in the medial parieto-occipital cortex (area V6A) of macaque monkey. Eur J Neurosci 22:956-972. CrossRef Medline

Fattori P, Pitzalis S, Galletti C (2009) The cortical visual area V6 in macaque and human brains. J Physiol Paris 103:88-97. CrossRef Medline

Fattori P, Raos V, Breveglieri R, Bosco A, Marzocchi N, Galletti C (2010) The dorsomedial pathway is not just for reaching: grasping neurons in the medial parieto-occipital cortex of the macaque monkey. J Neurosci 30: 342-349. CrossRef Medline

Ferraina S, Battaglia-Mayer A, Genovesio A, Marconi B, Onorati P, Caminiti R (2001) Early coding of visuomanual coordination during reaching in parietal area PEc. J Neurophysiol 85:462-467. Medline

Ferraina S, Paré M, Wurtz RH (2002) Comparison of cortico-cortical and 
cortico-collicular signals for the generation of saccadic eye movements. J Neurophysiol 87:845-858. Medline

Ferraina S, Brunamonti E, Giusti MA, Costa S, Genovesio A, Caminiti R (2009) Reaching in depth: hand position dominates over binocular eye position in the rostral superior parietal lobule. J Neurosci 29:1146111470. CrossRef Medline

Gallese V, Murata A, Kaseda M, Niki N, Sakata H (1994) Deficit of hand preshaping after muscimol injection in monkey parietal cortex. Neuroreport 5:1525-1529. CrossRef Medline

Galletti C, Fattori P, Gamberini M, Kutz DF (1999a) The cortical visual area V6: brain location and visual topography. Eur J Neurosci 11:3922-3936. CrossRef Medline

Galletti C, Fattori P, Kutz DF, Gamberini M (1999b) Brain location and visual topography of cortical area V6A in the macaque monkey. Eur J Neurosci 11:575-582. CrossRef Medline

Galletti C, Breveglieri R, Lappe M, Bosco A, Ciavarro M, Fattori P (2010) Covert shift of attention modulates the ongoing neural activity in a reaching area of the macaque dorsomedial visual stream. PLoS One 5:e15078. CrossRef Medline

Gallivan JP, McLean DA, Smith FW, Culham JC (2011) Decoding effectordependent and effector-independent movement intentions from human parieto-frontal brain activity. J Neurosci 31:17149-17168. CrossRef Medline

Gerbella M, Belmalih A, Borra E, Rozzi S, Luppino G (2011) Cortical connections of the anterior (F5a) subdivision of the macaque ventral premotor area F5. Brain Struct Funct 216:43-65. CrossRef Medline

Gnadt JW, Andersen RA (1988) Memory related motor planning activity in posterior parietal cortex of macaque. Exp Brain Res 70:216-220. Medline

Goldberg ME, Bushnell MC (1981) Behavioral enhancement of visual responses in monkey cerebral cortex. II. Modulation in frontal eye fields specifically related to saccades. J Neurophysiol 46:773-787. Medline

Gottlieb J, Goldberg ME (1999) Activity of neurons in the lateral intraparietal area of the monkey during an antisaccade task. Nat Neurosci 2:906912. CrossRef Medline

Hadjidimitrakis K, Bertozzi F, Breveglieri R, Bosco A, Galletti C, Fattori P (2014a) Common neural substrate for processing depth and direction signals for reaching in the monkey medial posterior parietal cortex. Cereb Cortex 24:1645-1657. CrossRef Medline

Hadjidimitrakis K, Bertozzi F, Breveglieri R, Fattori P, Galletti C (2014b) Body-centered, mixed, but not hand-centered coding of visual targets in the medial posterior parietal cortex during reaches in $3 \mathrm{D}$ space. Cereb Cortex 24:3209-3220. CrossRef Medline

Hagler DJ Jr, Riecke L, Sereno MI (2007) Parietal and superior frontal visuospatial maps activated by pointing and saccades. Neuroimage 35:15621577. CrossRef Medline

Heed T, Beurze SM, Toni I, Röder B, Medendorp WP (2011) Functional rather than effector-specific organization of human posterior parietal cortex. J Neurosci 31:3066-3076. CrossRef Medline

Hinkley LB, Krubitzer LA, Padberg J, Disbrow EA (2009) Visual-manual exploration and posterior parietal cortex in humans. J Neurophysiol 102: 3433-3446. CrossRef Medline

Janssen P, Shadlen MN (2005) A representation of the hazard rate of elapsed time in macaque area LIP. Nat Neurosci 8:234-241. CrossRef Medline

Janssens T, Zhu Q, Popivanov ID, Vanduffel W (2014) Probabilistic and single-subject retinotopic maps reveal the topographic organization of face patches in the macaque cortex. J Neurosci 34:10156-10167. CrossRef Medline

Johnson PB, Ferraina S, Bianchi L, Caminiti R (1996) Cortical networks for visual reaching: physiological and anatomical organization of frontal and parietal lobe arm regions. Cereb Cortex 6:102-119. CrossRef Medline

Kagan I, Iyer A, Lindner A, Andersen RA (2010) Space representation for eye movements is more contralateral in monkeys than in humans. Proc Natl Acad Sci U S A 107:7933-7938. CrossRef Medline

Kolster H, Mandeville JB, Arsenault JT, Ekstrom LB, Wald LL, Vanduffel W (2009) Visual field map clusters in macaque extrastriate visual cortex. J Neurosci 29:7031-7039. CrossRef Medline

Koyama M, Hasegawa I, Osada T, Adachi Y, Nakahara K, Miyashita Y (2004) Functional magnetic resonance imaging of macaque monkeys performing visually guided saccade tasks: comparison of cortical eye fields with humans. Neuron 41:795-807. CrossRef Medline

Kutz DF, Fattori P, Gamberini M, Breveglieri R, Galletti C (2003) Early- and late-responding cells to saccadic eye movements in the cortical area V6A of macaque monkey. Exp Brain Res 149:83-95. Medline

Lawrence BM, Snyder LH (2006) Comparison of effector-specific signals in frontal and parietal cortices. J Neurophysiol 96:1393-1400. CrossRef Medline

Leite FP, Mandeville JB (2006) Characterization of event-related designs using BOLD and IRON fMRI. Neuroimage 29:901-909. CrossRef Medline

Leite FP, Tsao D, Vanduffel W, Fize D, Sasaki Y, Wald LL, Dale AM, Kwong KK, Orban GA, Rosen BR, Tootell RB, Mandeville JB (2002) Repeated fMRI using iron oxide contrast agent in awake, behaving macaques at 3 Tesla. Neuroimage 16:283-294. CrossRef Medline

Leoné FT, Heed T, Toni I, Medendorp WP (2014) Understanding effector selectivity in human posterior parietal cortex by combining information patterns and activation measures. J Neurosci 34:7102-7112. CrossRef Medline

Levy I, Schluppeck D, Heeger DJ, Glimcher PW (2007) Specificity of human cortical areas for reaches and saccades. J Neurosci 27:4687-4696. CrossRef Medline

Marconi B, Genovesio A, Battaglia-Mayer A, Ferraina S, Squatrito S, Molinari M, Lacquaniti F, Caminiti R (2001) Eye-hand coordination during reaching. I. Anatomical relationships between parietal and frontal cortex. Cereb Cortex 11:513-527. CrossRef Medline

Matelli M, Luppino G, Rizzolatti G (1985) Patterns of cytochrome oxidase activity in the frontal agranular cortex of the macaque monkey. Behav Brain Res 18:125-136. CrossRef Medline

Medendorp WP, Goltz HC, Crawford JD, Vilis T (2005) Integration of target and effector information in human posterior parietal cortex for the planning of action. J Neurophysiol 93:954-962. Medline

Mountcastle VB, Lynch JC, Georgopoulos A, Sakata H, Acuna C (1975) Posterior parietal association cortex of the monkey: command functions for operations within extrapersonal space. J Neurophysiol 38:871-908. Medline

Munoz DP, Wurtz RH (1995) Saccade-related activity in monkey superior colliculus. I. Characteristics of burst and buildup cells. J Neurophysiol 73:2313-2333. Medline

Murata A, Gallese V, Luppino G, Kaseda M, Sakata H (2000) Selectivity for the shape, size, and orientation of objects for grasping in neurons of monkey parietal area AIP. J Neurophysiol 83:2580-2601. Medline

Nakamura K, Chung HH, Graziano MS, Gross CG (1999) Dynamic representation of eye position in the parieto-occipital sulcus. J Neurophysiol 81:2374-2385. Medline

Nelissen K, Vanduffel W (2011) Grasping-related functional magnetic resonance imaging brain responses in the macaque monkey. J Neurosci 31: 8220-8229. CrossRef Medline

Nelissen K, Luppino G, Vanduffel W, Rizzolatti G, Orban GA (2005) Observing others: multiple action representation in the frontal lobe. Science 310:332-336. CrossRef Medline

Nobre AC, Gitelman DR, Dias EC, Mesulam MM (2000) Covert visual spatial orienting and saccades: overlapping neural systems. Neuroimage 11: 210-216. CrossRef Medline

Noudoost B, Clark KL, Moore T (2014) A distinct contribution of the frontal eye field to the visual representation of saccadic targets. J Neurosci 34:3687-3698. CrossRef Medline

Peel TR, Johnston K, Lomber SG, Corneil BD (2014) Bilateral saccadic deficits following large and reversible inactivation of unilateral frontal eye field. J Neurophysiol 111:415-433. CrossRef Medline

Pesaran B, Pezaris JS, Sahani M, Mitra PP, Andersen RA (2002) Temporal structure in neuronal activity during working memory in macaque parietal cortex. Nat Neurosci 5:805-811. CrossRef Medline

Platt ML, Glimcher PW (1997) Responses of intraparietal neurons to saccadic targets and visual distractors. J Neurophysiol 78:1574-1589. Medline

Platt ML, Glimcher PW (1998) Response fields of intraparietal neurons quantified with multiple saccadic targets. Exp Brain Res 121:65-75. CrossRef Medline

Popivanov ID, Jastorff J, Vanduffel W, Vogels R (2012) Stimulus representations in body-selective regions of the macaque cortex assessed with event-related fMRI. Neuroimage 63:723-741. CrossRef Medline

Popivanov ID, Jastorff J, Vanduffel W, Vogels R (2014) Heterogeneous single-unit selectivity in an fMRI-defined body-selective patch. J Neurosci 34:95-111. CrossRef Medline

Premereur E, Vanduffel W, Janssen P (2011) Functional heterogeneity of 
macaque lateral intraparietal neurons. J Neurosci 31:12307-12317. CrossRef Medline

Premereur E, Janssen P, Vanduffel W (2013) FEF-microstimulation causes task-dependent modulation of occipital fMRI activity. Neuroimage 67: 42-50. CrossRef Medline

Raos V, Franchi G, Gallese V, Fogassi L (2003) Somatotopic organization of the lateral part of area F2 (dorsal premotor cortex) of the macaque monkey. J Neurophysiol 89:1503-1518. Medline

Rizzolatti G, Luppino G (2001) The cortical motor system. Neuron 31:889901. CrossRef Medline

Schall JD (2002) The neural selection and control of saccades by the frontal eye field. Philos Trans R Soc Lond B Biol Sci 357:1073-1082. CrossRef Medline

Schall JD, Morel A, King DJ, Bullier J (1995) Topography of visual cortex connections with frontal eye field in macaque: convergence and segregation of processing streams. J Neurosci 15:4464-4487. Medline

Scherberger H, Jarvis MR, Andersen RA (2005) Cortical local field potential encodes movement intentions in the posterior parietal cortex. Neuron 46:347-354. CrossRef Medline

Schiller PH, Sandell JH, Maunsell JH (1987) The effect of frontal eye field and superior colliculus lesions on saccadic latencies in the rhesus monkey. J Neurophysiol 57:1033-1049. Medline

Schlag J, Schlag-Rey M (1987) Evidence for a supplementary eye field. J Neurophysiol 57:179-200. Medline

Schluppeck D, Glimcher P, Heeger DJ (2005) Topographic organization for delayed saccades in human posterior parietal cortex. J Neurophysiol 94: 1372-1384. CrossRef Medline

Snyder LH, Batista AP, Andersen RA (1997) Coding of intention in the posterior parietal cortex. Nature 386:167-170. CrossRef Medline

Snyder LH, Batista AP, Andersen RA (2000) Intention-related activity in the posterior parietal cortex: a review. Vision Res 40:1433-1441. CrossRef Medline

Stanton GB, Bruce CJ, Goldberg ME (1995) Topography of projections to posterior cortical areas from the macaque frontal eye fields. J Comp Neurol 353:291-305. CrossRef Medline

Tehovnik EJ, Sommer MA, Chou IH, Slocum WM, Schiller PH (2000) Eye fields in the frontal lobes of primates. Brain Res Brain Res Rev 32:413448. CrossRef Medline

Thomas NW, Paré M (2007) Temporal processing of saccade targets in parietal cortex area LIP during visual search. J Neurophysiol 97:942-947. CrossRef Medline

Thompson KG, Biscoe KL, Sato TR (2005) Neuronal basis of covert spatial attention in the frontal eye field. J Neurosci 25:9479-9487. CrossRef Medline

Tsao DY, Freiwald WA, Tootell RB, Livingstone MS (2006) A cortical region consisting entirely of face-selective cells. Science 311:670-674. CrossRef Medline

Tsutsui K, Jiang M, Yara K, Sakata H, Taira M (2001) Integration of perspective and disparity cues in surface-orientation-selective neurons of area CIP. J Neurophysiol 86:2856-2867. Medline

Tsutsui K, Jiang M, Sakata H, Taira M (2003) Short-term memory and perceptual decision for three-dimensional visual features in the caudal intraparietal sulcus (Area CIP). J Neurosci 23:5486-5495. Medline

Van Der Werf J, Jensen O, Fries P, Medendorp WP (2008) Gamma-band activity in human posterior parietal cortex encodes the motor goal during delayed prosaccades and antisaccades. J Neurosci 28:8397-8405. CrossRef Medline

Van Der Werf J, Jensen O, Fries P, Medendorp WP (2010) Neuronal synchronization in human posterior parietal cortex during reach planning. J Neurosci 30:1402-1412. CrossRef Medline

Vanduffel W, Fize D, Mandeville JB, Nelissen K, Van Hecke P, Rosen BR, Tootell RB, Orban GA (2001) Visual motion processing investigated using contrast agent-enhanced fMRI in awake behaving monkeys. Neuron 32:565-577. CrossRef Medline

Vanduffel W, Zhu Q, Orban GA (2014) Monkey Cortex through fMRI Glasses. Neuron 83:533-550. CrossRef Medline

Vesia M, Crawford JD (2012) Specialization of reach function in human posterior parietal cortex. Exp Brain Res 221:1-18. CrossRef Medline

Wardak C, Olivier E, Duhamel JR (2002) Saccadic target selection deficits after lateral intraparietal area inactivation in monkeys. J Neurosci 22: 9877-9884. Medline 